\title{
Pathophysiology of Growth Hormone-Releasing Hormone (GHRH) Secretion in Humans
}

\author{
Kazuo CHIHARA, YoIchi KASHIO, Yasuhiko OKIMURA, \\ Michiaki SATO, Naoto KITAZIMA, Takuo FUJITA \\ AND MAtsuto MOCHIZUKI ${ }^{1}$
}

\author{
Third Division, Department of Medicine and ${ }^{1}$ Department of \\ Obstetrics and Gynecology, Kobe University School of \\ Medicine, Kobe 650, Japan
}

\begin{abstract}
Introduction
The existence of a growth hormone releasing-hormone (GHRH) has been postulated by the several lines of evidence that interruption of the connection between hypothalamus and pituitary results in a decrease in GH secretion in the rat, that electrical stimulation of the hypothalamic ventromedial and arcuate nucleus region of the rat stimulates $\mathrm{GH}$ secretion, that a crude hypothalamic extract stimulates $\mathrm{GH}$ secretion in vivo by its intrapituitary administration and in vitro from anterior pituitary in culture, and that pulsatile release of $\mathrm{GH}$ persists in rats passively immunized with antisomatostatin serum. In November 1982, GHRHs have been isolated and characterized from human pancreatic tumors producing GHRH ectopically. Pancreatic tumor-derived GHRHs have been subsequently demonstrated to be identical to human hypothalamic GHRHs. Historical backgrounds until discovery of GHRH were described in 4 excellent reviews (Reichlin et al., 1976; Vale et al., 1977; Gelato and Merriam, 1986; Frohman and Jansson, 1986).

In this article, we present our data concerning GHRH-like immunoreactivity (GHRH-LI) in plasma and cerebrospinal fluid as well as various tissues in humans and discuss physiological and pathogenetic aspects of GHRH secretion in humans.
\end{abstract}

\section{Radioimmunoassay for GHRH}

Details of our radioimmunoassay (RIA) system for GHRH are described elsewhere (Chihara et al., 1986). Our antiserum to GHRH was raised in New Zealand White rabbits by immunizing with $1 \mathrm{mg}$ synthetic human GHRH-(1-44)- $\mathrm{NH}_{2}$, conjugated to $2.5 \mathrm{mg}$ bovine thyroglobulin using $177 \mu \mathrm{g}$ glutaraldehyde. ${ }^{125}$ I-labeled hGHRH-(1-44)- $\mathrm{NH}_{2}$ was prepared by chloramine-Tmethod. Specific radioactivity ranged from $380-420 \mathrm{mCi} / \mathrm{mg}$. The solution containing suitable doubling dilutions of standard hGHRH-(1-44)- $\mathrm{NH}_{2}$ or sample specimens were preincubated with anti-GHRH serum at a final dilution of $1: 3,000,000$ in a total volume of $0.5 \mathrm{ml}$ RIA buffer $(0.05 \mathrm{M}$ phosphate buffer, $\mathrm{pH}$ 7.4, containing $0.08 \mathrm{M} \mathrm{NaCl}, 0.025 \mathrm{M}$ EDTA, $250 \mathrm{KIU} / \mathrm{ml}$ aprotinin, $1 \% \mathrm{BSA}$, and $0.1 \%$ Triton X-100) for $24 \mathrm{~h}$ at $4^{\circ} \mathrm{C}$, then $0.1 \mathrm{ml}$ 125I-hGHRH-(1-44)- $\mathrm{NH}_{2}$ (1-2 fmol) was added and further incubated for $72 \mathrm{~h}$ before 


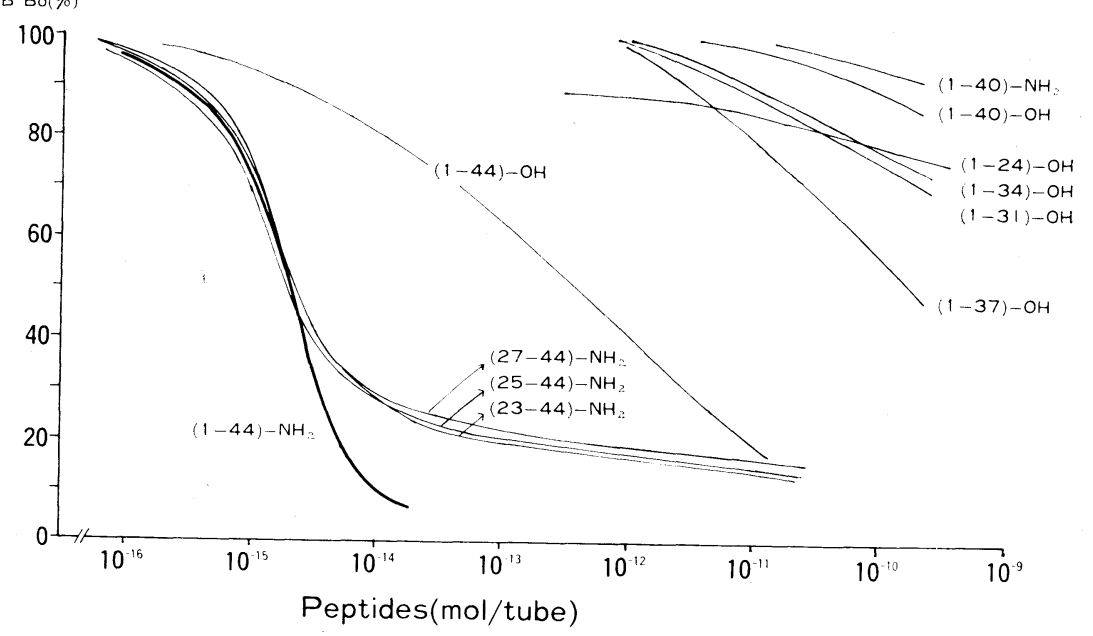

Fig. 1. Standard curve for hGHRH-(1-44)$\mathrm{NH}_{2}$ and crossreactivity studies.

separation by double antibody precipitation.

The limit of sensitivity for standard hGHRH-(1-44)- $\mathrm{NH}_{2}$ was $1 \mathrm{pg}$ or $0.2 \mathrm{fmol} /$ assay tube with the half-maximal displacement of tracer at $10 \mathrm{pg} /$ assay tube. The intra- and interassay coefficients of variation at a level of $15.6 \mathrm{pg}$ hGHRH-(1-44)- $\mathrm{NH}_{2}$ /assay tube were 7.4 and $12.6 \%$, respectively.

Our antiserum to GHRH did not crossreact with $\mathrm{N}$-terminal fragments including hGHRH-(1-37)-OH and hGHRH-(1-40)$\mathrm{OH}$. In contrast, C-terminal fragments such as hGHRH-(23-44)-NH $\mathrm{NH}_{2}$ hGHRH-(25-44)$\mathrm{NH}_{2}$ and hGHRH-(27-44)- $\mathrm{NH}_{2}$ had a crossreactivity of $100 \%$. Thus, the antigenic determinant site of our antiserum resided at the C-terminal portion of hGHRH-(1-44)$\mathrm{NH}_{2}$ (Fig. 1).

\section{Extraction of GHRH}

Tissues: Various tissues in humans, obtained at autopsy or surgery, were immediately frozen by liquid nitrogen and kept at $-20^{\circ} \mathrm{C}$ until extraction. When extracted, tissue samples were dropped into tubes containing 10 vol $2 \mathrm{~N}$ acetic acid immersed in a boiling water bath and maintained there for $10 \mathrm{~min}$. The tissues were then homogenized by a Polytron for $30 \mathrm{sec}$, sonicated for $30 \mathrm{~min}$ and the homogenates were centrifuged at $28,000 \times \mathrm{g}$ at $4^{\circ} \mathrm{C}$ for $20 \mathrm{~min}$. The supernatant was lyophilized. The recovery of the added hGHRH-(1-44)- $\mathrm{NH}_{2}$ in tissues was $89 \pm 5 \%($ mean $\pm \mathrm{SE}, \mathrm{n}=7)$.

Plasma: The blood was mixed with 500 kallikrein inhibitory units (KIU) aprotinin and $2.5 \mathrm{mg}$ EDTA per $\mathrm{ml}$ whole blood immediately after withdrawal; after centrifuging at $1000 \times \mathrm{g}$ for $10 \mathrm{~min}$, the plasma was kept at $-20^{\circ} \mathrm{C}$ until extraction. Extraction of GHRH from plasma was performed by silicic acid-acid-acetone method described previously (Chihara et al., 1986). Briefly, $10 \mathrm{mg}$ silicic acid per $\mathrm{ml}$ plasma were added to each tube containing plasma specimen and mixed for $30 \mathrm{~min}$ at $4^{\circ} \mathrm{C}$. The mixture was centrifuged at $1000 \times \mathrm{g}$ for $10 \mathrm{~min}$ at $4^{\circ} \mathrm{C}$. The supernatant was discarded and the pellet was washed twice with $1 \mathrm{ml}$ chilled distilled water $/ 10 \mathrm{mg}$ silicic acid. The GHRH was eluted from the pellet using $1 \mathrm{ml} 0.1 \mathrm{~N}$ $\mathrm{HCl}$-acetone $(1: 4) / 10 \mathrm{mg}$ silicic acid. To this eluate the same volume of petroleum ether was added, mixed, with a vortex mixer, and centrifuged at $1000 \times \mathrm{g}$ for $5 \mathrm{~min}$ at $4^{\circ} \mathrm{C}$. After removing the organic layer by careful 
aspiration, the aqueous layer was completely dried in a Speed-Vac Concentrator (Savant Instrument, Inc. Hicksville, NY). The recovery of the added hGHRH-(1-44)- $\mathrm{NH}_{2}$ in plasma was $72 \pm 4 \%$ (mean $\pm S E, n=7)$.

Cerebrospinal fuid: Cerebrospinal fluid (CSF) samples were collected in a routine lumbar puncture procedure, immediately mixed with $500 \mathrm{KIU}$ aprotinin and $2.5 \mathrm{mg}$ EDTA per $\mathrm{ml}$ of the CSF and kept at $-20^{\circ} \mathrm{C}$. The CSF samples were extracted by acid-acetone method. One $\mathrm{mg}$ of BSA was added into $2 \mathrm{ml}$ of the CSF samples to prevent adsorption of GHRH to tubes and then the mixture was dried in a Speed-Vac Concentrator. Two ml of $0.1 \mathrm{~N} \mathrm{HCl}$ acetone $(1: 4)$ solution was added to each tube containing the dried CSF sample, agitated with vortex mixer, centrifuged at $2,500 \times \mathrm{g}$ for $10 \mathrm{~min}$ at $4^{\circ} \mathrm{C}$ and the supernatant was dried in a Speed-Vac Concentrator. The recovery of the added hGHRH-(1-44)- $\mathrm{NH}_{2}$ in CSF was $43 \pm 3 \%$ $($ mean $\pm S E, n=5)$.

\section{Characterization of GHRH-like immunoreactivity in extracts}

When serial dilutions of extracts of pituitary stalk, median eminence and the remaining hypothalamus were assayed, the resulting inhibition curves were parallel with that of synthetic hGHRH-(1-44)- $\mathrm{NH}_{2}$. Typical dilution curves of the extracts of tissues, obtained at autopsy of a patient with malignant lymphoma, were shown in Fig. 2. Extracts of plasma and CSF yielded displacement curves which were completely parallel with the standard curve of hGHRH(1-44) $-\mathrm{NH}_{2}$, as reported previously (Chihara et al., 1986; Kashio et al., 1985). These findings suggest that GHRH-LI in extracts of hypothalamic tissues and plasma as well as CSF is immunologically not different from ${ }^{3}$ GHRH-(1-44)- $\mathrm{NH}_{2}$ molecule.

To examine the molecular size of GHRH-

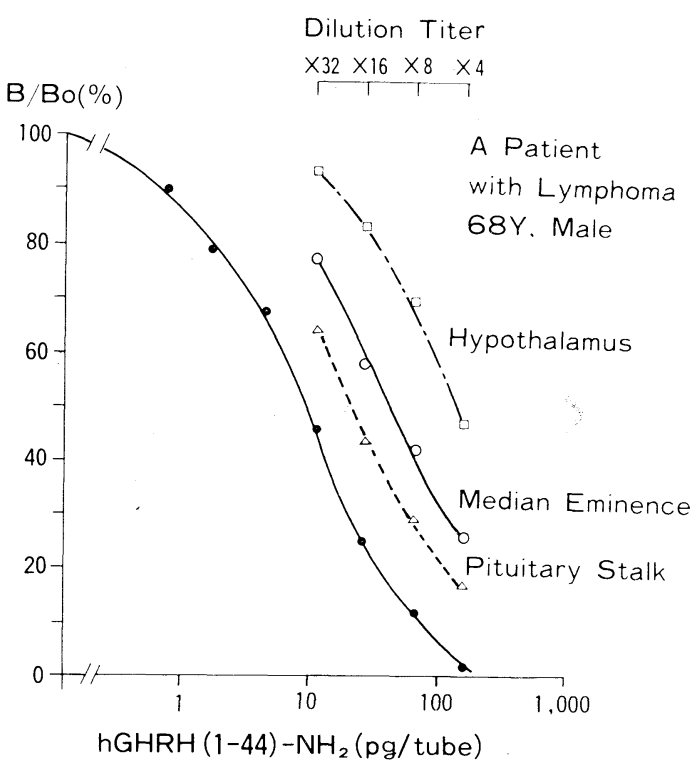

Fig. 2. Serial dilutions of the extracts of pituitary stalk, median eminence and the remaining hypothalamus gave parallel inhibition curves.

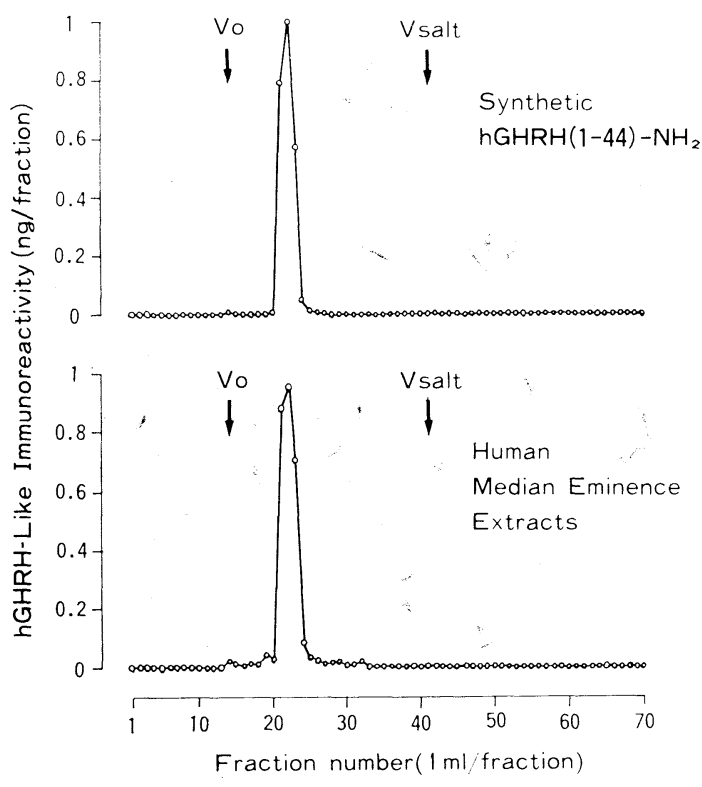

Fig. 3. Sephadex G-50 gel filtration of the extracts of human median eminence. A single peak of the GHRH-LI in the extracts coeluted with synthetic hGHRH-(1-44)-- $\mathrm{NH}_{2}$. The void volume $(\mathrm{Vo})$ and total bed volume $(\mathrm{Vt})$ were determined with blue dextram and $\mathrm{NaCl}$, respectively. 
LI in extracts, the extracts of human median eminence were chromatographed on a Sephadex G-50 column $(0.8 \times 100 \mathrm{~cm})$ using $1 \mathrm{~N}$ acetic acid containing $0.1 \%$ BSA as the eluant. As shown in Fig. 3, a single peak of GHRH-LI was eluted, corresponding to hGHRH-(1-44)- $\mathrm{NH}_{2}$. Similar findings were observed on Sephadex G-50 gel filtration chromatographies of the extracts of plasma (Chihara et al., 1986) and CSF (Kashio et al., 1985). Therefore, GHRHLI in the extracts of hypothalamic tissues, plasma and CSF appeared to have a similar molecular size with hGHRH-(1-44)- $\mathrm{NH}_{2}$. However, it remains unclarified whether GHRH-LI in extracts is bioactive, since the levels have been insufficient to permit validation by bioassay for GHRH. Ling et al. (1984) have extracted GHRH from several thousand stalk median eminence fragments of human pituitary and hypothalamus origin and proved the presence of the peptide identical to hGHRH-(1-44)- $\mathrm{NH}_{2}$ in human hypothalamus using a gas-phase sequencer and reverse-phase high performance liquid chromatography (HPLC).

In patients with ectopic GHRH-producing tumor, plasma GHRH levels are sufficiently high to permit validation by HPLC. Penny et al. (1985) have reported that reversephase HPLC of Vycor-extracted plasma resolved the GHRH-LI into three components, which coeluted with hGHRH-(140)-OH (69\%), hGHRH-(1-44)- $\mathrm{NH}_{2}(22 \%)$ and hGHRH-(1-37)-OH (9\%). In normal subjects, it was difficult to characterize GHRH-LI in peripheral plasma because of its low levels, while plasma GHRH-LI levels were determined by several laboratories (Penny et al., 1984; Saito et al., 1984; Frohman 1984; Audhya et al., 1985; Thorner et al., 1985), In our recent study (Chihara et al., 1986), freshly prepared pools of plasma containing EDTA and trasylol were extracted according to the antibody affinity technique, and the lyophilized extracts were chromatographed on a Sephadex G-50 column with $0.1 \%$ BSAcontaining $1 \mathrm{~N}$ acetic acid. When the single GHRH-LI peak, detected by gel chromatography of plasma extracts, was further analyzed by HPLC on a Nucleosil $5 \mathrm{C}_{18}$ reverse phase column, the major single peak of GHRH-LI emerged at the area where synthetic hGHRH-(1-44)- $\mathrm{NH}_{2}$ eluted. On the other hand, it has been very recently reported that hGHRH-(1-44)- $\mathrm{NH}_{2}$ is converted to a less hydrophobic peptide, hGHRH-(3-44)- $\mathrm{NH}_{2}$ immediately after exposure to plasma in vivo and in vitro (Frohman et al., 1986). Whether hGHRH(3-44) $-\mathrm{NH}_{2}$ is distinguishable from the hGHRH-(1-44)- $\mathrm{NH}_{2}$ in our column condition of HPLC remains unclarified.

\section{Distribution of GHRH-like immunore- activity in various tissues of humans}

The concentration of GHRH-LI in the extracts of various tissues in humans is shown in Fig. 4. The highest concentration of GHRH-LI was detected in extracts of median eminence, in which GHRH-LI level ranged $124-800 \mathrm{pg} / \mathrm{mg}$ wet weight of tissue with a mean $\pm S E$ value of $388.7 \pm 108.7 \mathrm{pg} /$ $\mathrm{mg}$ tissue. The high concentration of GHRHLI, comparable to that in median eminence, was also found in pituitary stalk $(282.9 \pm$ $99.7 \mathrm{pg} / \mathrm{mg}$ tissue), which is consistent with previous works from other laboratories (Lin et al., 1984; Shibasaki et al., 1984). A small but significant amount of GHRH-LI was detected in extracts of anterior pituitary $(6.2 \pm 2.2 \mathrm{pg} / \mathrm{mg}$ tissue $)$ and posterior pituitary $(4.2 \pm 1.5 \mathrm{pg} / \mathrm{mg}$ tissue). These results are compatible with the possibility that GHRH is secreted from nerve terminals of GHRH-containing neurons into hypophysial portal vessels in median eminence, transported by portal blood to the pituitary and bound with the receptors for GHRH on samatotrophs. Morel et al. (1984) demonstrated the presence of GHRH-LI in the 

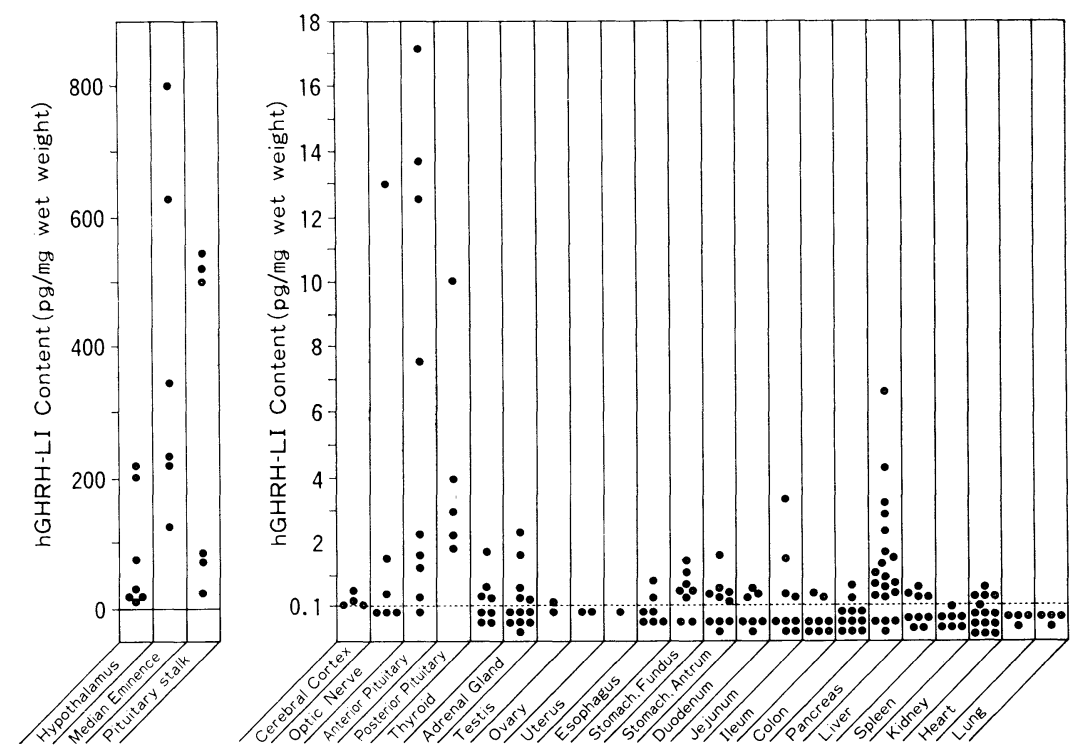

Fig. 4. Concentration of GHRH-LI in various tissues of humans.

monkey somatotroph using immunohistochemical technique. The hypothalamus excluding median eminence contained considerably high concentration of GHRH-LI $(75.3 \pm 34.4 \mathrm{pg} / \mathrm{mg}$ tissue), whereas GHRHLI level in extracts of cerebral cortex was negligible. The spinal cord, medulla oblongata, pons, thalamus and cerebellum contained no detectable amounts of GHRHLI (data not shown). Thus, GHRH is localized in small area of the brain, while somatostatin and TRH as well as corticotropin-releasing factor are widely distributed throughout the brain. Regarding this restricted distribution, GHRH is more closely similar to LHRH, but the distribution of GHRH in the central nervous system is even more limited than that of LHRH.

Among extrahypothalamic sites containing GHRH-LI, pancreas showed a wide range of GHRH-LI concentration from undetectable level to $6.6 \mathrm{pg} / \mathrm{mg}$ tissue, suggesting uneven distribution of GHRH-LI in pancreas (Fig. 4). In immunohistochemical studies GHRH-LI colocalizes with pancreatic polypeptide in the cells which are located in the area corresponding to the ventral primordium of the pancreas while a GHRHcontaining cells is not found in other area of the pancreas (Saito H. and S. Saito, personal communication). Extracts of the stomach, duodenum, jejunum, thyroid, adrenal, liver and kidney contained a low concentration of GHRH-LI. The presence of GHRH-LI in the upper intestinal tract is demonstrated by immunohistochemical studies (Bosman et al., 1984). GHRH-LI colocalizes with gastrin in the gastric antrum of humans. Only in rat duodenum have characterization studies using HPLC shown the identity with GHRH (Bruhn et al., 1985).

\section{Concentration of GHRH-like immunoreactivity in plasma}

Fetal pituitary tissue content of $\mathrm{GH}$ is high, 1000 times that of PRL, LH and FSH, reflecting the preponderance of somatotrophic cells in the fetal gland. The levels increase with gestational age, rising from less than $1 \mu \mathrm{g} / \mathrm{gland}$ at 10 weeks to greater 
than $600 \mu \mathrm{g} / \mathrm{gland}$ at term. There is little change in pituitary GH content during the first year of life (Kaplan and Grumback,1976). GH-containing cells have been identified in the human fetal anterior pituitary as early as the 7th week of gestation (Li el al., 1977). $\mathrm{GH}$ are detectable in circulating blood as early as the 10th week of gestation. Plasma $\mathrm{GH}$ levels rise rapidly, reaching a peak at 20 to 24 weeks, and decrease thereafter until birth (Matsuzaki et al., 1971). However, plasma GH levels in umbilical cord blood remain significantly higher than maternal levels and within the range observed with acromegalic patients (Matsuzaki et al., 1971). GHRH-LI has been reported in the infundibular nucleus as early as 18 weeks of gestation (Bresson et al., 1984). Therefore, GH secretion during the initial stage of gestation may be independent of GHRH. As shown in Fig. 5, however, GHRH-LI level in plasma samples obtained from the umbilical cord vessels was markedly elevated. Plasma GHRH-LI level in the umbilical artery (mean $\pm S E, 47.4 \pm 4.7 \mathrm{pg} / \mathrm{ml}$, $\mathrm{n}=15$ ) was high, 1.7 times that in the umbilical vein $(28.5 \pm 2.5 \mathrm{pg} / \mathrm{ml}, \mathrm{n}=22)$. A significant gradient in plasma GHRH-LI level between umbilical arterial and venous blood was observed in 15 babied examined. Although there was no correlation between GH and GHRH-LI level in the same cord blood (data not shown), elevated GHRH-LI level in circulating blood presumably relates with enhanced secretion of $\mathrm{GH}$ from the pituitary during neonatal peroid. The important role of GHRH in the physiological control of $\mathrm{GH}$ secretion during neonatal period is suggested by animal experiments using passive immunization technique in which the elevated levels of $\mathrm{GH}$ occurred within a few hours of birth can be significantly suppressed by the injection of antiGHRH serum in rats (Frohman et al., 1986).

GHRH-LI was detectable in peripherally circulating blood in normal subjects. After an overnight fast, mean \pm SE base-line levels of plasma GHRH-LI were $14.7 \pm 0.8 \mathrm{pg} / \mathrm{ml}$ in normal male adults $(\mathrm{n}=50)$ and $14.4 \pm$ $1.0 \mathrm{pg} / \mathrm{ml}$ in normal female adults $(\mathrm{n}=46)$, indicating no sex difference in baseline level of plasma GHRH-LI. In prepubertal children, basal plasma GHRH-LI level was $7.3 \pm 0.6 \mathrm{pg} / \mathrm{ml} \quad(\mathrm{n}=40)$, significantly lower than that in adults. Similar findings were

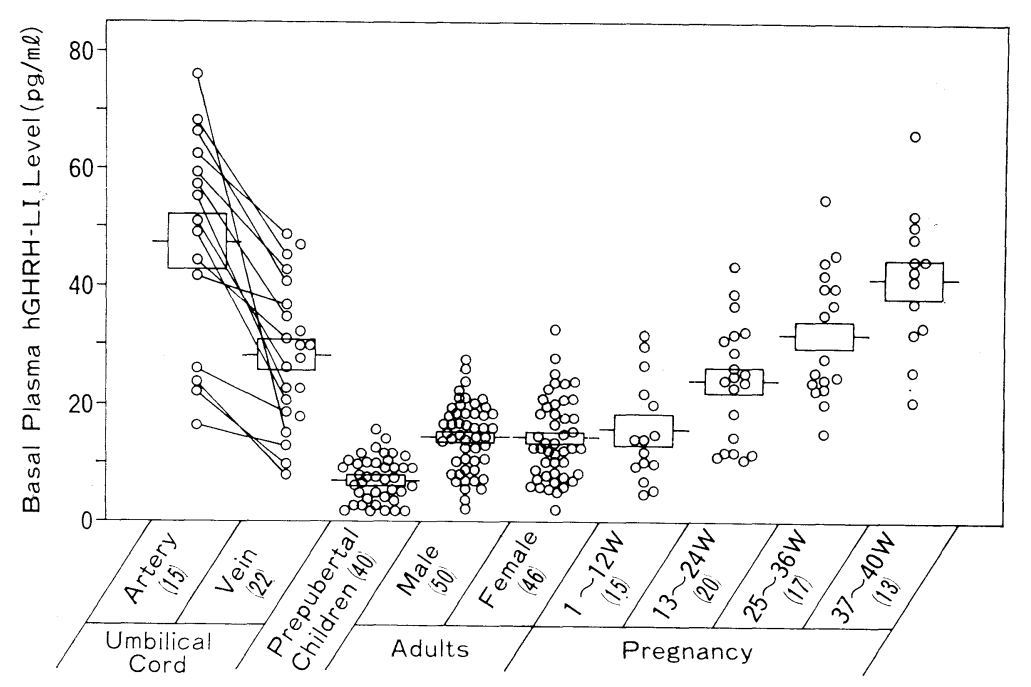

Fig. 5. Plasma GHRHLI level in umbilical cord blood and in peripheral blood of prepubertal children, adults and pregnant women. Mean \pm SE and individual values are shown. Number of the plasma samples is shown in parentheses. 
recently reported by J. Argente et al. (1986). Pulsatile GH secretion with high amplitude occurs during pubertal development whereas the plasma GH secretory episode is scanty before puberty (Finkelstein et al., 1972). In prepubertal children, therefore, few GH secretory episodes possibly relate with low GHRH-LI level in circulating plasma which may suggest the low secretion rate of hypothalamic GHRH.

We found for the first time that plasma GHRH-LI concentration increased with month of gestation, highest GHRH-LI level being obtained at term of pregnancy (Fig. 5). Since plasma GH levels do not change throughout pregnancy, it is unlikely that the source of increased GHRH-LI in pregnancy is the hypothalamus. Concerning this, an immunologically and biologically active GHRH that was indistinguishable from hypothalamic GHRH has been identified in rat placenta (Baired et al., 1985). Thus, production of GHRH in placenta may cause an increase in plasma GHRH-LI level during pregnancy, although there have been no convincing reports of the presence of GHRH in human placenta.

\section{Plasma GHRH-LI concentration during provocation test for $\mathrm{GH}$ release}

Basal levels of plasma GHRH-LI were considerably variable from subject to subject, but changed little during a 120-min observation period in control studies. Therefore, the effect of various stimuli on GHRH secretion was evaluated by the net changes of plasma GHRH-LI level from the basal values. Oral ingestion of 1-dopa $(0.5 \mathrm{~g})$ and clonidine $(150 \mu \mathrm{g})$ as well as insulininduced hypoglycemia (regular insulin $0.1 \mathrm{U} /$ $\mathrm{kg} \mathrm{BW}$, iv) caused a significant increase in both GHRH-LI and GH in the plasma of normal adults (Fig. 6). The increase in plasma GHRH-LI slightly preceded or coincided with that in plasma GH. In contrast, arginine-induced GH release was not preceded by a GHRH rise, but was accompanied with a transient GHRH

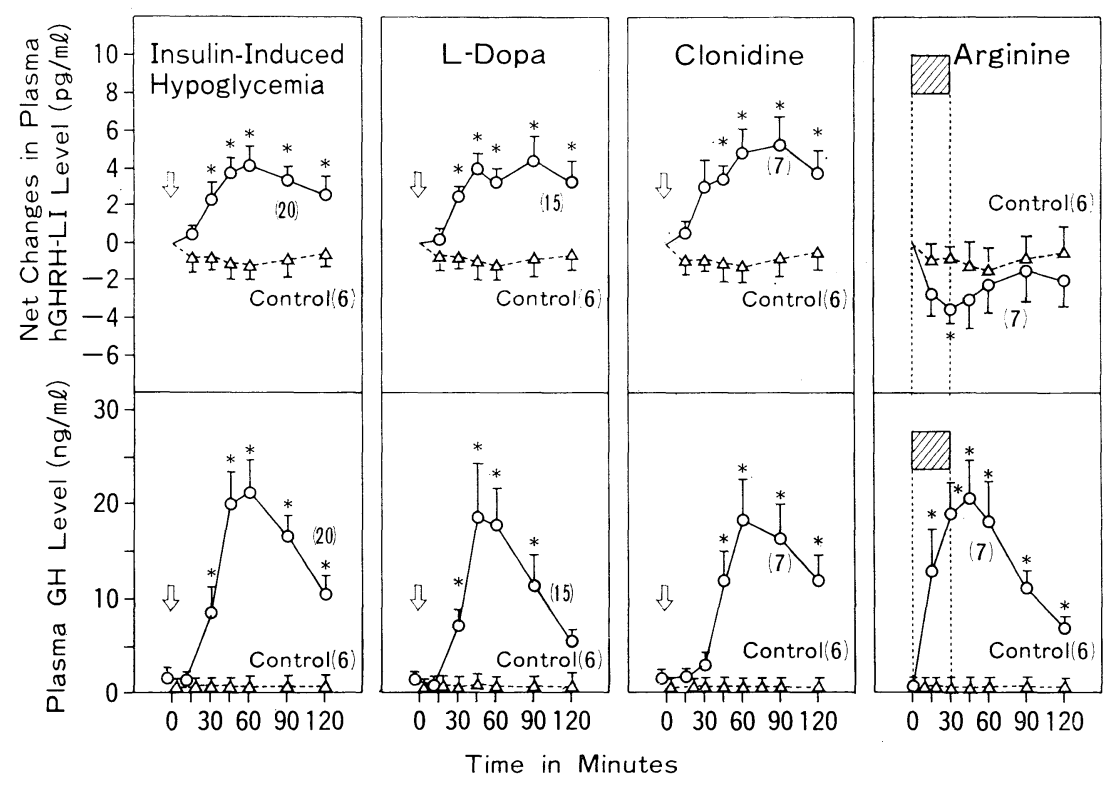

Fig. 6. Plasma GHRH$\mathrm{LI}$ and $\mathrm{GH}$ response to insulin-induced hypoglycemia (regular insulin $0.1 \mathrm{U} / \mathrm{kg}$ BW, iv), 1-dopa (0.5 $\mathrm{g}, \mathrm{po})$, clonidine $(150 \mu \mathrm{g}, \mathrm{po})$ and arginine $(0.5 \mathrm{~g} / \mathrm{kg} \mathrm{BW}$, iv, infusion for 30 $\mathrm{min}$ ) in normal adults. Statistical difference ( $v s$ control) is shown by asterisks : * $\mathbf{P}<0.05$. 


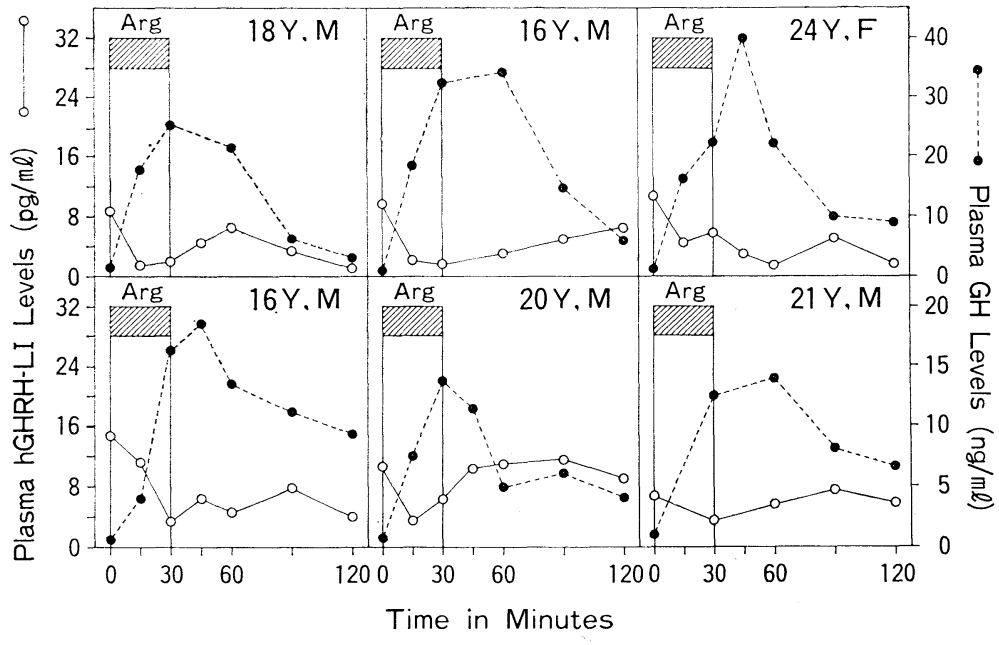

$\because$ Patients with Hypothalamic Lesion $\bigcirc$ Normal Control Subjects

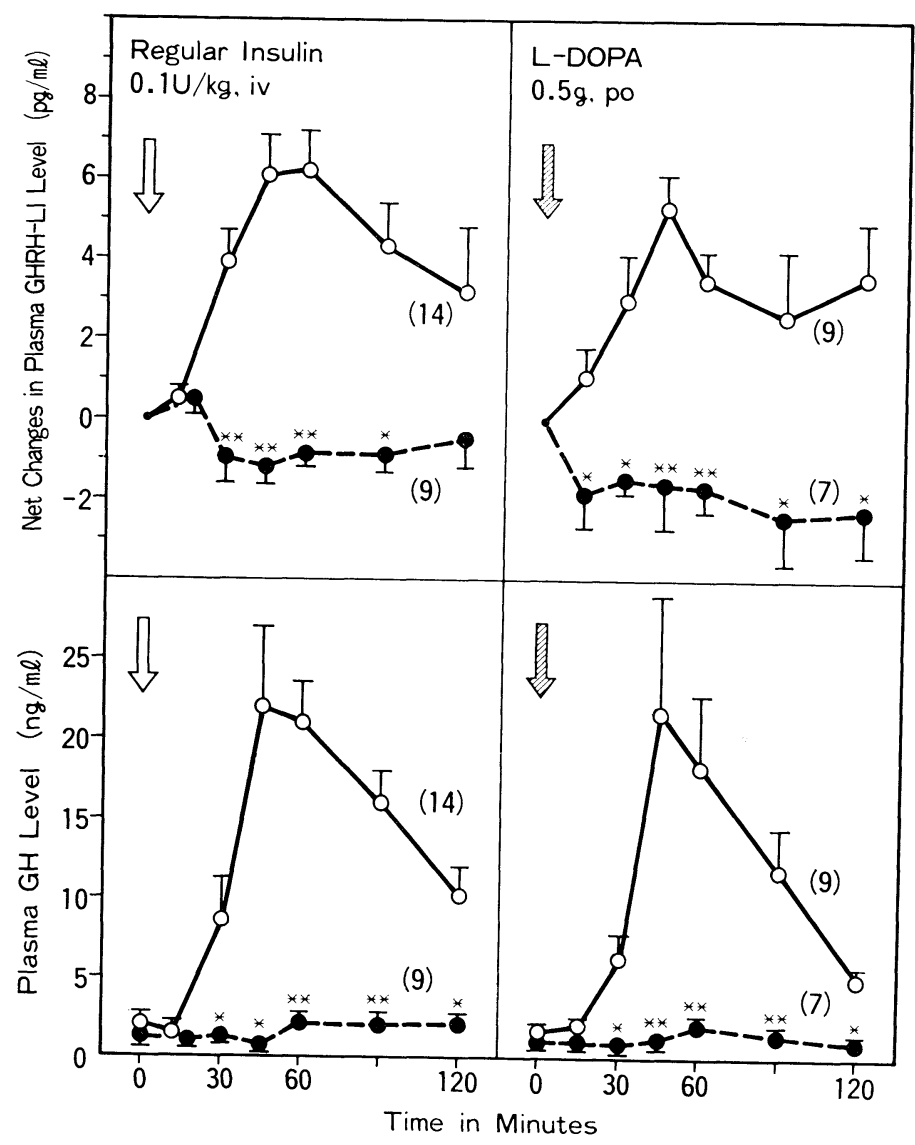

Fig. 7. The patterns of plasma GHRH-LI and $\mathrm{GH}$ response to a 30 min-iv infusion of arginine $(0.5 \mathrm{~g} / \mathrm{kg} \mathrm{BW})$ in six individual normal subjects.
Fig. 8. Effect of insulininduced hypoglycemia and 1-dopa ingestion on plasma GHRH-LI and $\mathrm{GH}$ concentrations in patients with hypothalamic lesion and age-matched normal subjects. Statistical difference ( $v s$ normal subjects) is shown by asterisks : $* \mathbf{P}<0.01$. 
decrease. The patterns of plasma GHRH$\mathrm{LI}$ and $\mathrm{GH}$ responses to arginine in six individual normal subjects were shown in Fig. 7. Dissociation of the plasma GHRH$\mathrm{LI}$ and $\mathrm{GH}$ response has been reported in ornithine test for GH stimulation (Donnadieu et al., 1985).

To clarify the source of GHRH-LI increased in the peripheral plasma during $\mathrm{GH}$ stimulation tests, the effect of insulininduced hypoglycemia and 1-dopa ingestion on plasma GHRH-IL levels was examined in patients with damaged hypothalamus resulting from germinoma, craniopharyngioma, meningioma, irradiation and so on. The patients with hypothalamic lesions participating in this study were strictly selected according to the following two criteria : first, plasma GH peak levels had to exceed $8 \mathrm{ng} / \mathrm{ml}$ after an iv bolus injection of hGHRH-(1-44)- $\mathrm{NH}_{2}(1 \mu \mathrm{g} / \mathrm{kg} \mathrm{BW})$, indicating the presence of functioning somatotrophs; and second, the maximum levels of plasma GH were not to exceed 3 $\mathrm{ng} / \mathrm{ml}$ after 1-dopa ingestion and insulininduced hypoglycemia. In these patients, neither 1-dopa ingestion nor insulin-induced hypoglycemia raised plasma GHRH-LI levels (Fig. 8). These findings suggest not only that the source of increased GHRH-LI in the plasma after 1-dopa ingestion and insulin-induced hypoglycemia is the hypothalamus, but also that the release by various stimuli of hypothalamic GHRH into the hypophysial portal circulation is reflected in changes in peripheral GHRH-LI levels.

The precise mechanism by which 1-dopa stimulates $\mathrm{GH}$ release remains still unclear. L-Dopa is supposed to stimulate $\mathrm{GH}$ release via the central dopaminergic and $\alpha$ adrenergic mechanisms (Martin et al., 1978). Furthermore, there are several lines of evidence in animal experiments suggesting involvement of $\alpha$-adrenergic mechanisms in the control of hypothalamic GHRH release. Spontaneous episodes of GH release in conscious rabbits are abolished by pretreat- ment with phenoxybenzamine, an $\alpha$ adrenergic antagonist, and this suppression of spontaneous GH pulses occurs in animals pretreated with antisomatostatin serum (Chihara et al., 1984). In addition, stimulation of $\mathrm{GH}$ release by clonidine, a centrally active $\alpha$-adrenergic agonist, is completely blunted in rats pretreated with antiserum to GHRH (Miki et al., 1984). All of these findings support the hypothesis that the activation of central $\alpha$-adrenergic receptors causes stimulation of GHRH release from the hypothalamus. Our results in the present study that 1-dopa stimulates the release of hypothalamic GHRH-LI in humans suggest universality of this hypothesis beyond species differences.

Insulin-induced hypoglycemia seems to exert $\mathrm{GH}$ release by a different way from 1-dopa ingestion. Since insulin-induced hypoglycemia caused an increase in plasma GHRH-LI level in normal subjects but not in patients with hypothalamic lesions, hypoglycemic stress is supposed to stimulate GHRH release from the hypothalamus. However, when the net increments in plasma GHRH-LI and the plasma GH response after the stimulation were integrated throughout the 120-min observation period by planimetry of curves depicting the plasma GHRH-LI and GH levels as a function of time, a significant correlation was evident in 1 -dopa ingestion test $(\mathrm{r}=0.510, \mathrm{P}<0.02$, $\mathrm{n}=22$ ) but not in insulin-induced hypoglycemia $(r=0.318$, statistically not significant, $\mathrm{n}=28$ ) as shown in Fig. 9. On analysis of the patterns of plasma GHRH$\mathrm{LI}$ and $\mathrm{GH}$ response to hypoglycemic stress in individual subjects, we found the presence of a considerable number of subjects in whom insulin-induced hypoglycemia stimulated $\mathrm{GH}$ release without a concomitant increase of plasma GHRH-LI level, suggesting the involvement of other mechanisms of hypoglycemia-induced GH release. Recently, Shibasaki et al. (1985) and Vance et al. (1986) suggested that insulin-induced hy- 


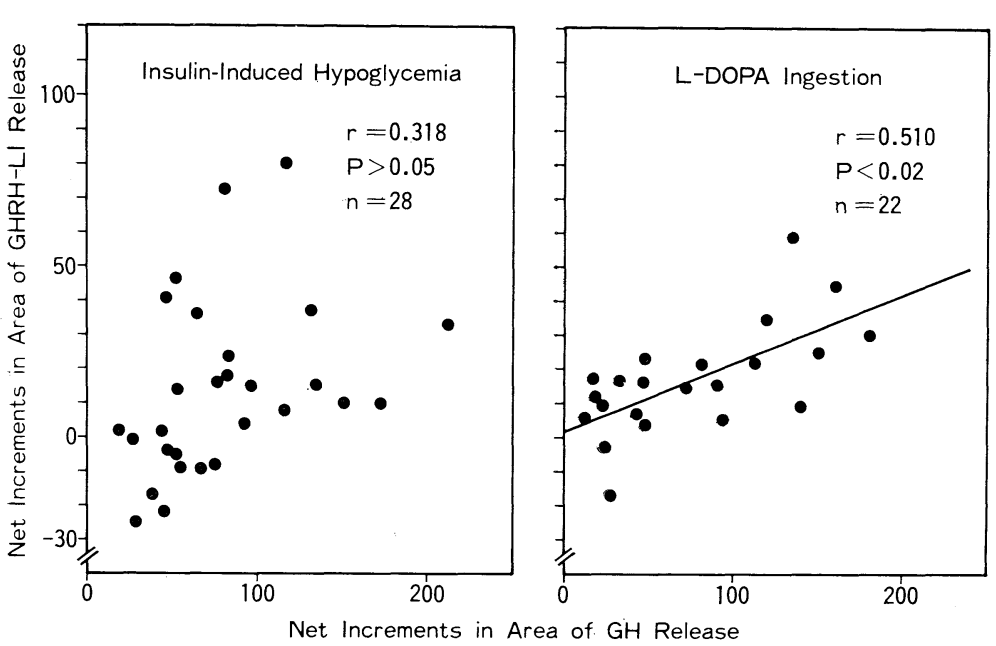

April 1986

Fig. 9. Correlation between plasma GHRH-LI and $\mathrm{GH}$ responses to insulininduced hypoglycemia or 1-dopa ingestion in normal subjects. Net increments in area of release were expressed in arbitrary units, as determined by planimetry of curves depicting the net increase in plasma hormone level from the basal value throughout a 120-min period after 1 dopa ingestion as a function of time. poglycemia may cause an increase of plasma $\mathrm{GH}$ by inhibition of somatostatin release. Therefore, the GH release induced by hypoglycemia may result from 2 different mechanisms, namely enhanced GHRH release and suppression of somatostatin release.

On the other hand, there is no convincing explanation about the mechanism of arginine-induced $\mathrm{GH}$ release. Since arginine administration failed to increase plasma GHRH-LI level in spite of marked rises in plasma GH, it is unlikely that arginine stimulates the release of GHRH from the hypothalamus. Thus, two possibilities remain to elucidate it: first, arginine may inhibit the release of somatostatin from the hypothalamus, and second, arginine may stimulate $\mathrm{GH}$ release by its direct action on the somatotrophs. Surprisingly, there is no reports regarding the effect of arginine on $\mathrm{GH}$ release from the pituitary in vitro.

\section{Release of GHRH-LI from extra- hypothalamic source}

As mentioned previously, GHRH-LI is present not only in the hypothalamus but also in other tissues, particularly the gastroenteropancreatic (GEP) system. One of the source of GHRH-LI in circulating plasma is definitely the hypothalamus. However, GHRH-LI is present in the peripheral plasma of patients with hypothalamic lesions in amounts comparable to those in normal subjects (Chihara et al., 1986), indicating that the source of circulating GHRH is not restricted to the hypothalamus. Accordingly, we studied the effect of glucose administration on plasma GHRH-LI, GH, insulin and blood glucose in 12 normal men (Fig. 10). In the control study, in which blood was collected every $30 \mathrm{~min}$ for $6 \mathrm{~h}$ from 8 of the 12 normal subjects without ingesting glucose, blood glucose and plasma insulin levels changed little throughout the $6 \mathrm{~h}$ observation period. Mean plasma GH levels did not change significantly, although 7 of the 8 normal subjects had sporadic episodes of plasma $\mathrm{GH}$ rises above $2.0 \mathrm{ng} / \mathrm{ml}$. Plasma GHRH-LI levels (mean basal value : 13.5 \pm 1.6 (SEM) $\mathrm{pg} / \mathrm{ml}, \mathrm{n}=8$ ) did not change significantly during the $6 \mathrm{~h}$-control study, although 2-3 small pulses (net increments $>$ $4 \mathrm{pg} / \mathrm{ml}$ ) of plasma GHRH-LI occurred during the $6 \mathrm{~h}$-control study in most subjects. As shown in Fig. 10, the mean net 


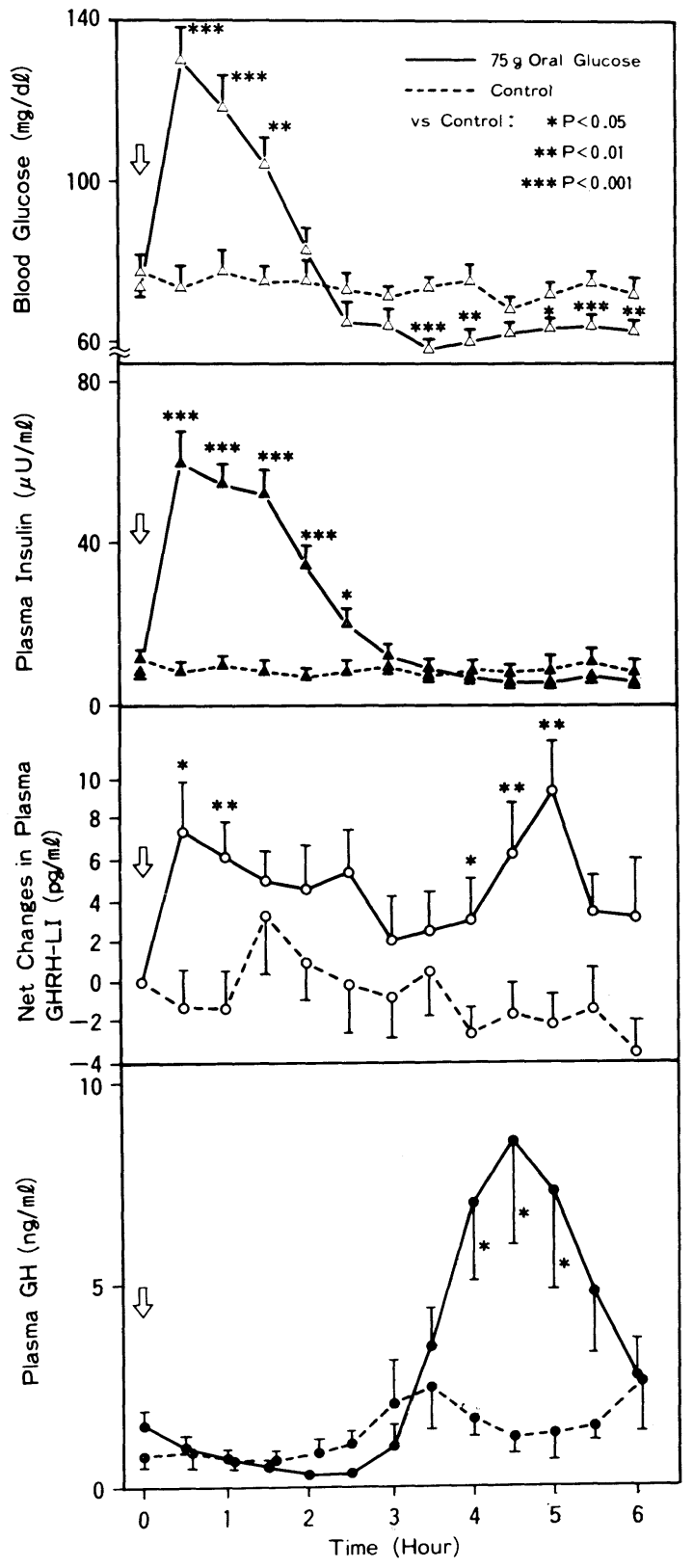

Fig. 10. Changes in blood glucose and plasma insulin (IRI), GHRH-LI and GH levels after $75 \mathrm{~g}$ oral glucose administration in normal subjects. The numbers of the subjects participating in OGTT and control study were 12 and 8 , respectively. Statistical difference ( $v S$ the control study) is shown by asterisks. increment in plasma GHRH-LI 30 min after glucose ingestion, $7.4 \pm 2.4 \mathrm{pg} / \mathrm{ml}$, was significantly greater than that in the control study $(-1.1 \pm 1.8 \mathrm{pg} / \mathrm{ml}, \mathrm{P}<0.05)$. After $3 \mathrm{~h}$, plasma insulin returned to the basal level and blood glucose levels were somewhat lower than those in the control study. Blood glucose levels were significantly lower $3.5 \mathrm{~h}$ after glucose ingestion and remained significantly lower thereafter. Simultaneously with development of this reactive hypoglycemia, plasma GH and GHRH-LI levels significantly increased, with a $\mathrm{GH}$ peak of $8.4 \pm 2.6 \mathrm{ng} / \mathrm{ml}$ and a GHRH-LI net increment of $9.4 \pm 2.4 \mathrm{pg} / \mathrm{ml}$ (Fig. 10).

Next, to clarify whether the source of the increased plasma GHRH-LI due to glucose ingestion is the hypothalamus, the effect of oral glucose administration on plasma GHRH-LI levels was examined in the patients with idiopathic GH deficiency (IGHD) who had impaired hypothalamic GHRH secretion. As discussed later in this paper, the primary defect causing IGHD is variable, and may be the impaired hypothalamic GHRH release and/or some abnormalities in the somatotroph. In this study, therefore, we chose patients with IGHD resulting from the decreased hypothalamic GHRH release on the basis of findings that peripheral plasma GHRH-LI levels failed to increase in response to stimuli which would cause hypothalamic GHRH secretion, such as 1-dopa and insulin-induced hypoglycemia. The patterns of plasma GHRH-LI to insulin-induced hypoglycemia in the selected patients with IGHD were shown in Fig. 11. In these patients, oral glucose administration produced only a single plasma GHRH-LI rise occurring 30-150 min after the ingestion, but not the second GHRH-LI rises accompanying plasma $\mathrm{GH}$ increases $3-6 \mathrm{~h}$ after glucose ingestion in normal subjects (Fig. 12). It has been speculated that stimulation of $\mathrm{GH}$ release $3-6 \mathrm{~h}$ after glucose ingestion is triggered by the reactive 


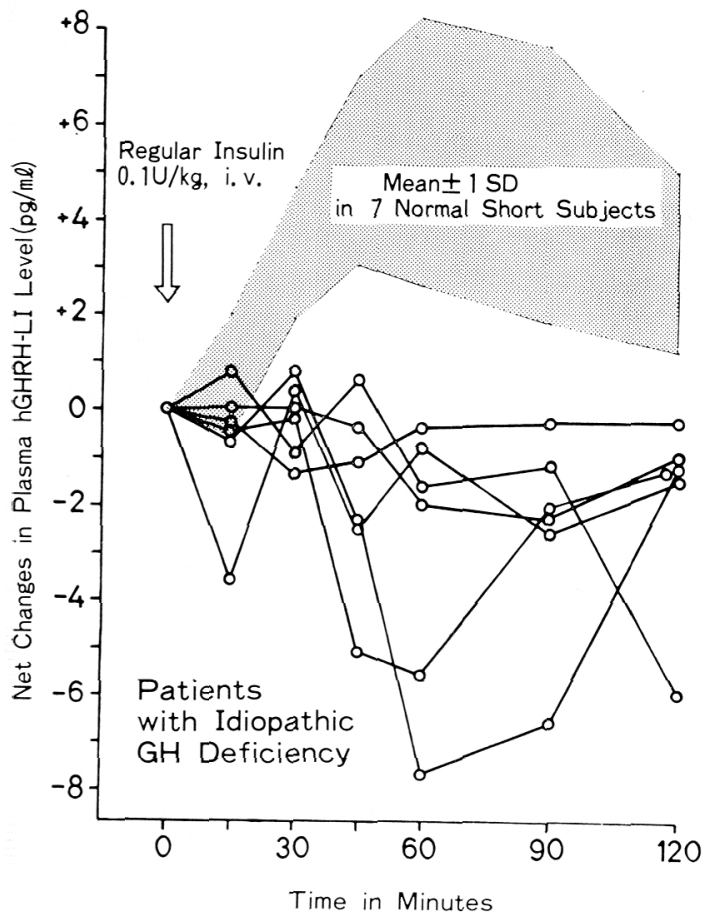

Fig. 11. The patterns of plasma GHRH-LI response to insulin-induced hypoglycemia in 6 patients with $\mathrm{GH}$ deficiency. A shadow illustrates mean \pm SD plasma GHRH-LI levels expressed as the net change from the basal value in short but otherwise normal children.

hypoglycemia. This is consistent with findings that insulin-induced hypoglycemia failed to increase plasma GH and GHRH-LI levels in these IGHD patients. Therefore the main source of the plasma GHRH-LI increase 3-6 h after oral glucose administration is probably the hypothalamus.

On the other hand, it is unlikely that the source of increased plasma GHRH-LI $30-150 \mathrm{~min}$ after glucose ingestion is the hypothalamus, since these GHRH-LI rises occurred also in patients with IGHD, in whom GHRH secretion from the hypothalamus was impaired. It remains unclarify which extrahypothalamic organ is responsible for the plasma GHRH-LI rises shortly after glucose ingestion. As mentioned

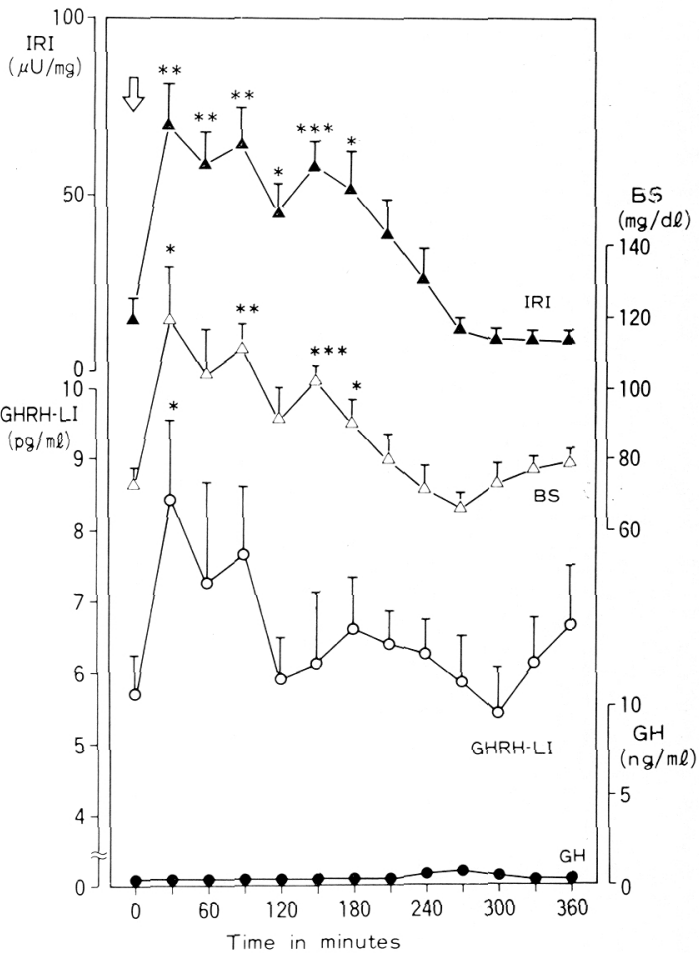

Fig. 12. Changes in blood glucose and plasma insulin (IRI), GHRH-LI and GH levels after $75 \mathrm{~g}$ glucose ingestion in 6 patients with idiopathic GH deficiency who had impaired hypothalamic GHRH secretion. Statistical difference ( $v s$ basal value) is shown by asterisks.

previously, abundant GHRH-LI was found in the GEP system, and the first plasma GHRH-LI rises after glucose ingestion synchronized with elevation of plasma IRI and blood glucose. These findings are consistent with the possibilility that the main source of GHRH-LI increases after glucose ingestion is the GEP system. Furthermore, we found that an iv injection of glucose $(50 \%, 20 \mathrm{ml})$ failed to raise plasma GHRH-LI levels despite of development of the increase in both blood glucose and plasma insulin which was comparable to that after oral glucose administration (Kashio and Chihara, unpublished observation). Also, mechanical distension of the stomach by ingesting 
tap water of the same volume as glucose solution used in $75 \mathrm{~g}$ OGTT failed to change plasma GHRH-LI levels. Therefore, the contact of glucose with inner surface of the alimentary canal appeared to be crucial for triggering GHRH-LI release from the GEP system.

The physiological role of GHRH in the GEP system remains unknown. Pandol et al. (1984) found the receptors for GHRH in the pancreatic acini of guinea pigs, through which GHRH may stimulate pancreatic enzyme secretion. The close relationship between the blood glucose, and plasma insulin and GHRH-LI responses to oral glucose was demonstrated in this study. In a preliminary study, we found that the increases in blood glucose and plasma insulin by oral glucose administration were slightly but significantly suppressed by an iv injection of synthetic GHRH-(1-44)$\mathrm{NH}_{2}(1 \mu \mathrm{g} / \mathrm{kg} \mathrm{BW}) 30 \mathrm{~min}$ before glucose ingestion. These findings suggest some role of GHRH in regulating glucose homeostasis via the GEP system.

\section{GHRH and GH-deficient dwarfism}

GH deficiency (GHD), defined as the state of impaired $\mathrm{GH}$ secretion from the pituitary, can be divided into two general categories, termed organic and idiopathic.
Organic GHD is defined as GHD resulting from an intracranial lesion; idiopathic GHD occurs in the absence of any specific underlying anatomical abnormality. It has been proposed that most of the GHD of idiopathic origin may be attributed to a defect in GHRH output from the hypothalamus (Goodman et al., 1968), but it could also result from intrinsic somatotroph abnormalities. To verify this proposal, plasma GH response to exogenously injected GHRH and GHRH-LI levels in the plasma as well as cerebrospinal fluid (CSF) were examined in 28 idiopathic GHD children. Twenty-five of 28 idiopathic GH deficient children had a history of breech delivery with severe and prolonged asphyxia. Short but otherwise normal children served as the control. As another control, we selected the seven GHD children with hypothalamic germinoma who had impaired GHRH secretion.

All of the normal children with short stature had increases in plasma GH exceeding $5 \mathrm{ng} / \mathrm{ml}$ after the single iv bolus dose of $1 \mu \mathrm{g} / \mathrm{kg} \mathrm{GHRH}-(1-44)-\mathrm{NH}_{2}$. Plasma $\mathrm{GH}$ responses to GHRH in patients with germinoma or idiopathic GHD were significantly lower than that in short normal children (Chihara et al., 1985). Furthermore, plasma GH rises after GHRH injection in idiopathic GHD children were significantly less than those in patients with hypothalamic germinoma (Chihara et al.,

\section{GH Deficiency Secondary to Idiopathic GH Deficiency Hypothalamic Germinoma}
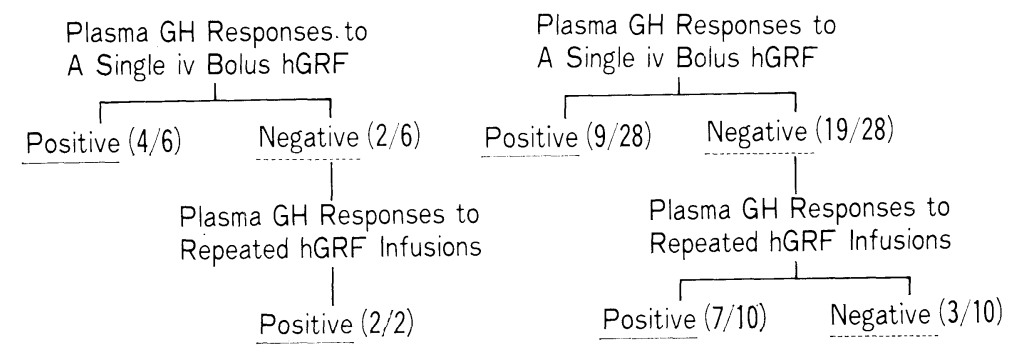

Fig. 13. Summary of the plasma $\mathrm{GH}$ responses to a single iv bolus injection of $1 \mu \mathrm{g} / \mathrm{kg} \mathrm{GHRH}-(1-44)$ $\mathrm{NH}_{2}$ and those to repeated three daily 1 -h iv infusions of $2 \mu \mathrm{g} / \mathrm{kg} \quad \mathrm{GHRH}$ in children with either idiopathic GHD or GHD secondary to hypothalamic germinoma. 
1985). When the increases in plasma GH more than $5 \mathrm{ng} / \mathrm{ml}$ after GHRH administration were defined as a positive GH response, four of six children with germinoma had a positive $\mathrm{GH}$ response to a single iv bolus injection of GHRH and the remaining two children failed to respond (Fig. 13). On the other hand, positive $\mathrm{GH}$ responses to a single iv bolus GHRH occurred in 9 (32\%) of the 28 children with idiopathic GHD, and the remaining 19 children $(68 \%)$ had little or no response of plasma $\mathrm{GH}$ to the single bolus dose of GHRH (Fig. 13). The obvious rise of plasma $\mathrm{GH}$ after 2 single bolus injection of GHRH in some GHD patients indicates that at least some of their somatotrophs are functional. Since their plasma GH responses to insulininduced hypoglycemia and 1-dopa were absent, the primary defect in these GHD patients is probably in the hypothalamus. An absent or very small GH response to a single bolus injection of GHRH, however, does not necessarily indicate a pituitary lesion, since the impaired $\mathrm{GH}$ response to GHRH may be attributable to hyporesponsiveness of pituitary somatotrophs due to chronic GHRH deficiency. Barinaga et al. (1983) reported that GHRH stimulates transcription of the $\mathrm{GH}$ gene as well as $\mathrm{GH}$ release. Therefore, severe deprivation of endogenous GHRH probably causes abolition of $\mathrm{GH}$ biosynthesis, and consequently, pituitary GH reserve is exhausted. In this situation, a single bolus injection of GHRH may fail to elicit GH release, but repeated administration of GHRH might activate $\mathrm{GH}$ biosynthesis and, thus, plasma GH responsiveness to GHRH. Next, therefore, we examined the effect on $\mathrm{GH}$ release of treatment with three daily $1-\mathrm{h}$ iv in-

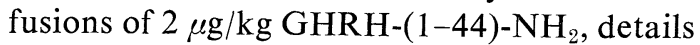
of which are described previously (Chihara et al., 1985). Plasma GH levels increased during the infusion of GHRH on 3 successive days in the two children with GHD secondary to germinoma who failed to respond to a single dose of GHRH, indicating that all of the six GHD patients with germinoma were responsive to exogenously administered GHRH.

On the other hand, the daily iv infusions of GHRH resulted in significant rises of plasma GH in seven of ten idiopathic GHD children who failed to respond to the first iv bolus dose of GHRH. The pattern of restoration of the $\mathrm{GH}$ response during daily GHRH infusions in these seven idiopathic GHD children was similar to that in the two patients with germinoma who responded to repeated GHRH injection, suggesting that prolonged deprivation of endogenous GHRH may cause GHD in these children with idiopathic GHD. In three children with the idiopathic GHD, however, three daily iv infusions of GHRH failed to increase plasma $\mathrm{GH}$ levels greater than $5 \mathrm{ng} /$ $\mathrm{ml}$. These patients would be suspected to have a primary pituitary disorder. In

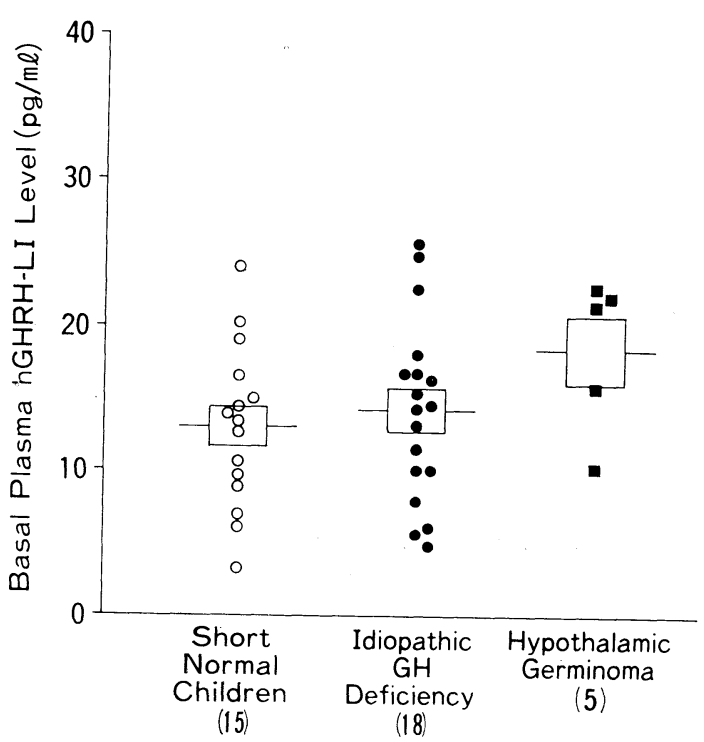

Fig. 14. Basal GHRH-LI levels in the peripheral plasma in short but otherwise normal children, idiopathic GHD children and the children with GHD secondary to hypothalamic germinoma. Horizontal bars and squares represent the mean and SEM, respectively. 


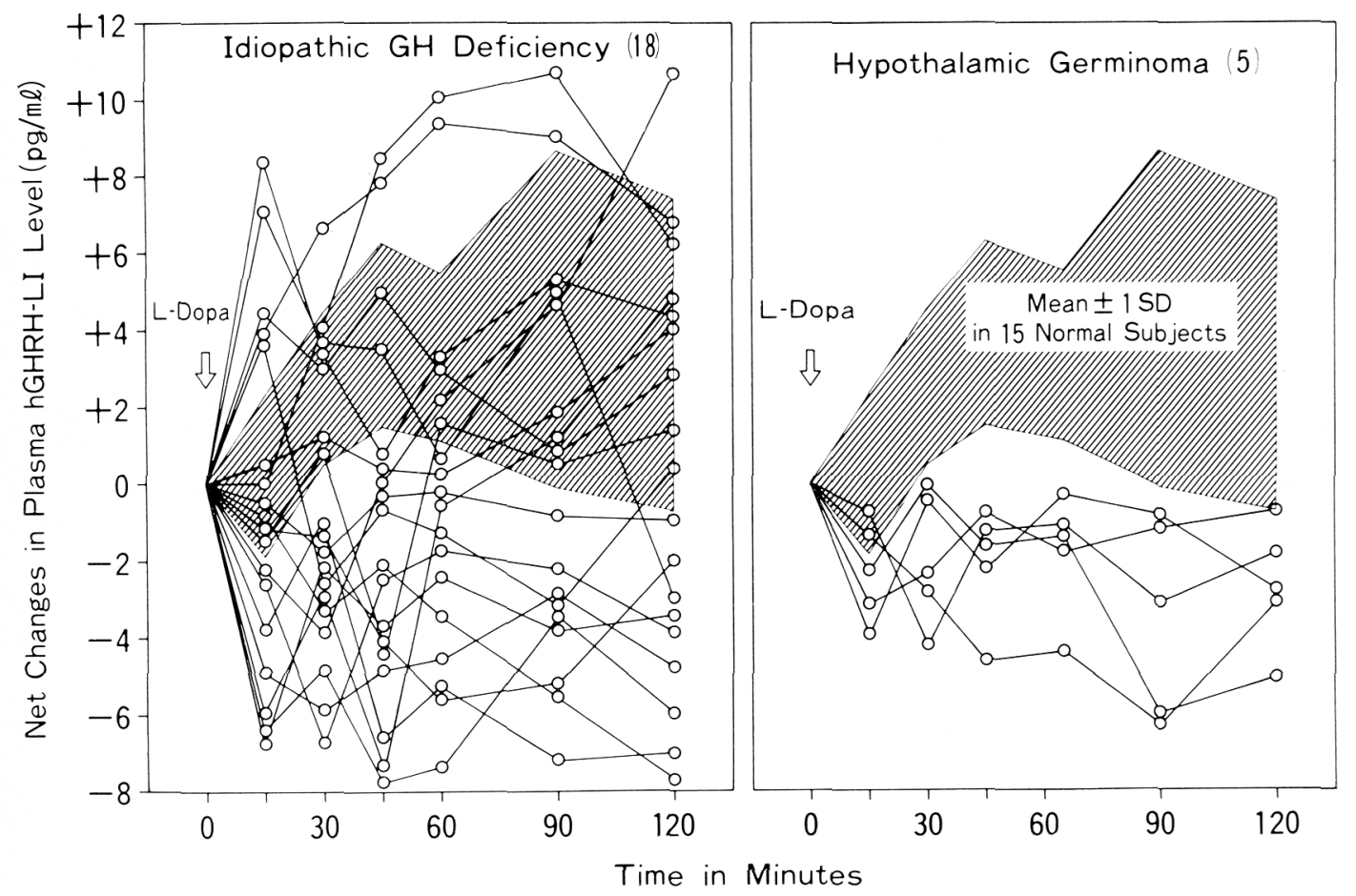

Fig. 15. Patterns of plasma GHRH-LI responses to 1-dopa ingestion in idiopathic GHD children and the GHD children with hypothalamic germinoma. The net changes in plsama GHRH-LI level from the basal value are shown. The area enclosed by a fine line represents the mean $\pm S D$ value of net change in plasma GHRH-LI level after 1-dopa ingestion in short but otherwise normal children.

summary, $100 \%$ of GHD children secondary to hypothalamic germinoma responded to exogenously administered GHRH and approximately $80 \%$ of idiopathic GHD children responded to exogenous GHRH (Fig. 13).

Basal GHRH-LI levels in peripheral plasma overlapped each other between short normal children $(13.0 \pm 1.4 \mathrm{pg} / \mathrm{ml})$ and idiopathic GHD children $(14.2 \pm 1.4 \mathrm{pg} / \mathrm{ml})$ (Fig. 14). Basal plasma GHRH-LI levels in GHD children with hypothalamic germinoma $(18.4 \pm 2.4 \mathrm{pg} / \mathrm{ml})$ were also not different from those in the other two groups. Oral administration of 1 -dopa $(10 \mathrm{mg} / \mathrm{kg} \mathrm{BW}$ or maximumly $0.5 \mathrm{~g}$ ) caused significant increases in plasma GHRH-LI as well as plasma GH in normal short children, whereas 1-dopa ingestion failed to increase plasma GHRH-LI levels in GHD children with hypothalamic germinoma (Fig. 15 and 16). The net increment in plasma GHRHLI from the basal level in children with germinoma, $-1.1 . \pm 0.5 \mathrm{pg} / \mathrm{ml}$ was significantly lower than that in short normal children $(5.5 \pm 0.8 \mathrm{pg} / \mathrm{ml}, \mathrm{P}<0.001)$. On the other hand, the plasma GHRH-LI response to 1-dopa ingestion was highly variable in idiopathic GHD children: seven of eighteen children with idiopathic GHD (39\%) showed low GHRH-LI levels after 1-dopa stimulation which were comparable with those in children with germinoma and, in the remaining eleven children $(61 \%)$, plasma GHRH-LI levels increased after 1-dopa 


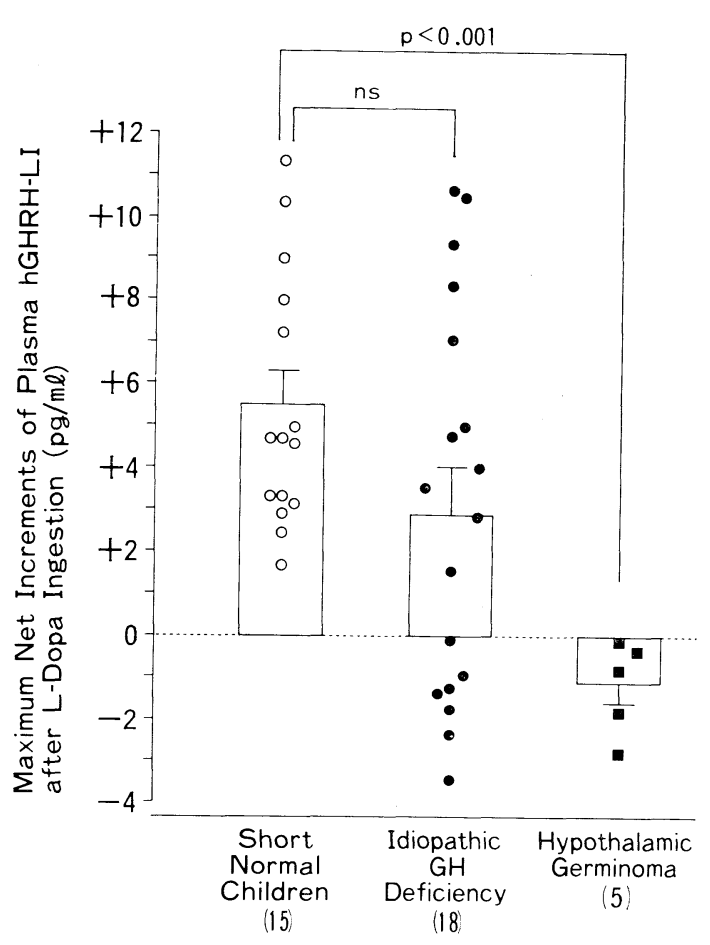

Fig. 16. Maximum net increments of plasma GHRH-LI after 1-dopa ingestion in short normal children, idiopathic GHD children and the GHD children with hypothalamic germinoma. Columns and vertical bars represent the mean and SEM, respectively.

ingestion by the values comparable with those in short normal children (Fig. 16). Therefore, the mean net increment in plasma GHRH-LI after 1-dopa ingestion in idiopathic GHD children, $2.9 \pm 1.1 \mathrm{pg} / \mathrm{ml}$ was not different from that in short normal children.

The concentration of GHRH-LI in CSF in normal subjects ranged from 10.2-33.5 $\mathrm{pg} / \mathrm{ml}$ with a mean value of $23.2 \pm 1.1$ (SE) $\mathrm{pg} / \mathrm{ml}$ (Fig. 17). GHRH-LI level in CSF in short normal children, $20.6 \pm 1.9 \mathrm{pg} / \mathrm{ml}$ was not different from that in normal subjects. In GHD children with hypothalamic germinoma, GHRH-LI level in the CSF $(9.1 \pm 1.6$ $\mathrm{pg} / \mathrm{ml}$ ) was significantly low as compared

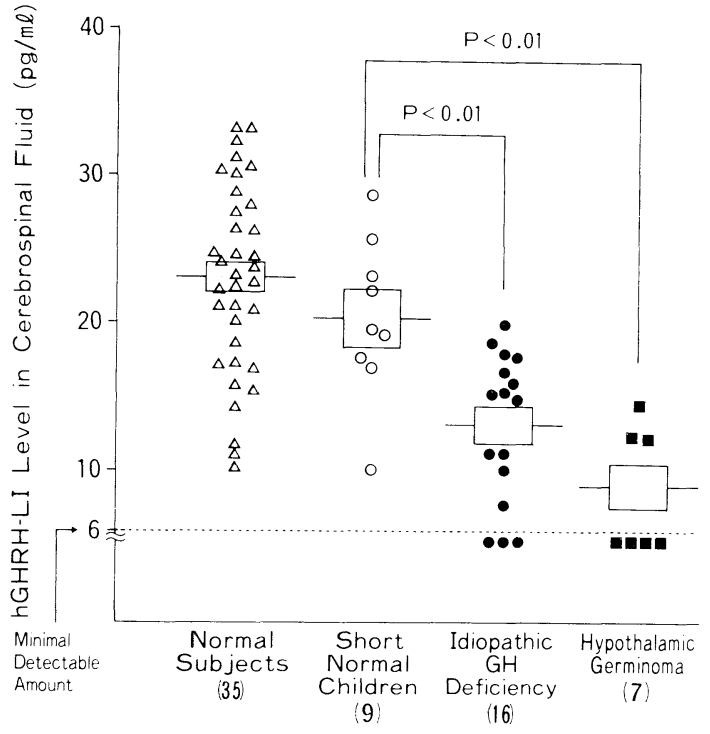

Fig. 17. Concentration of GHRH-LI in the cerebrospinal fluid in normal subjects (adult), short normal children, idiopathic GHD children and the GHD children with hypothalamic germinoma. Horizontal bars and squares represent the mean and SEM, respectively.

with that in short normal children. GHRHLI was not detectable $(<6 \mathrm{pg} / \mathrm{ml})$ in the CSF in four of the seven children with germinoma. In idiopathic GHD children, GHRH-LI level in the CSF widely ranged from undetectable level to the level in short normal children as did the plasma GHRH-LI response to 1-dopa. The mean GHRH-LI level in the CSF in idiopathic GHD children, $15.7 \pm 0.9 \mathrm{pg} / \mathrm{ml}$ was significantly lower than that in short normal children.

From these results, GHD secondary to destruction of hypothalamic GHRH neurons, like hypothalamic germinoma, might be characterized by the following 3 endocrinological findings; 1) undetectable or extremely low levels of GHRH-LI in the CSF ; 2) lack of peripheral plasma GHRH$\mathrm{LI}$ and $\mathrm{GH}$ response to the standard provocative tests acting through the hypo- 
thalamus, like 1-dopa and insulin-induced hypoglycemia; and 3) significant increase in plasma GH after a single bolus and/or repeated iv administration of GHRH.

On the other hand, the results of our studies have not entirely clarified the nature of the defect in idiopathic GHD. The average GHRH-LI level in the CSF in idiopathic GHD children was significantly lower than that in short normal children, suggesting the decreased hypothalamic GHRH secretion in idicpathic GHD. However, approximately half of idiopathic GHD children had the GHRH-LI level in the CSF comparable with that in short normal children. Furthermore, GHRH-LI rises in peripheral plasma after 1-dopa ingestion blunted in 39\% of idiopathic GHD children and occurred in $61 \%$ of them. On the other hand, about $80 \%$ of idiopathic GHD children showed a plasma $\mathrm{GH}$ increase exceeding $5 \mathrm{ng} / \mathrm{ml}$ after a single bolus and/or repeated iv administration of GHRH, suggesting the presence of at least some of functional somatotrophs in most of idiopathic GHD children. However, the secretory reserve for $\mathrm{GH}$ in their pituitary is not completely intact as that in normal children, since the $\mathrm{GH}$ responders to a single bolus GHRH in idiopathic GHD had a significant lower plasma GH peak level in an average than in short normal children after a single bolus iv injection of GHRH and, furthermore, the majority of non- or minimal responders to a single bolus GHRH did not increase $\mathrm{GH}$ secretion with plasma $\mathrm{GH}$ peak exceeding $10 \mathrm{ng} / \mathrm{ml}$ substantially after repeated iv administration of GHRH (unpublished observations). It is undoubted, therefore, that GH secretory reserve in the pituitary is virtually decreased in idiopathic GHD. A decreased pituitary GH pool is possibly attributed to marked reductions in hypothalamic GHRH secretion as mentioned previously. Alternately, permanent changes causing a decreased GH reserve may be present at the pituitary in idiopathic GHD children. The latter possibility seems to be more probable, because minimal $\mathrm{GH}$ responders failed to restore normal $\mathrm{GH}$ response patterns to GHRH even after the replacement therapy with GHRH mimicked a physiological GHRH secretory profile (Borges et al., 1984; Gelato et al., 1985). Thus, permanent impairment in pituitary somatotrophs as well as hypothalamic damage is suspected in majority of idiopathic GHD children examined in our study, most of whom have a history of abnormal delivery.

\section{GHRH and Acromegaly}

Overproduction of $\mathrm{GH}$ by $\mathrm{GH}$-secreting pituitary tumors does not necessarily imply autonomy. Most patients with acromegaly remain responsive to GHRH (Wood et al., 1983; Shibasaki et al., 1984 ; Gelato et al., 1985). It is of interest to know whether endogenous GHRH in the hypothalamus play a role in maintaining the activity of GH-producing adenoma cells. For this purpose, we measured GHRH-LI levels in the peripheral plasma and CSF in 30 patients with acromegaly. Twenty patients were in an active phase, and ten patients continued an inactive phase after successful treatment. Four of twenty active acromegalics and four of ten inactive patients received radiation therapy in the past. As shown in Fig. 18, plasma GH levels in active acromegalic patients without receiving radiation therapy were markedly elevated, ranging from $9.8-86.0 \mathrm{ng} / \mathrm{ml}$ with a mean value of $29.7 \pm 5.5(\mathrm{SEM}) \mathrm{ng} / \mathrm{ml}$. Active acromegalic patients previously treated with radiation had a lower plasma $\mathrm{GH}$ level $(9.6 \pm 1.9 \mathrm{ng} / \mathrm{ml})$ than those without radiotherapy. Plasma GH levels in acromegalic patients in an inactive phase were below $5 \mathrm{ng} / \mathrm{ml}$.

Basal GHRH-LI levels in peripheral plasma in patients with acromegaly were 


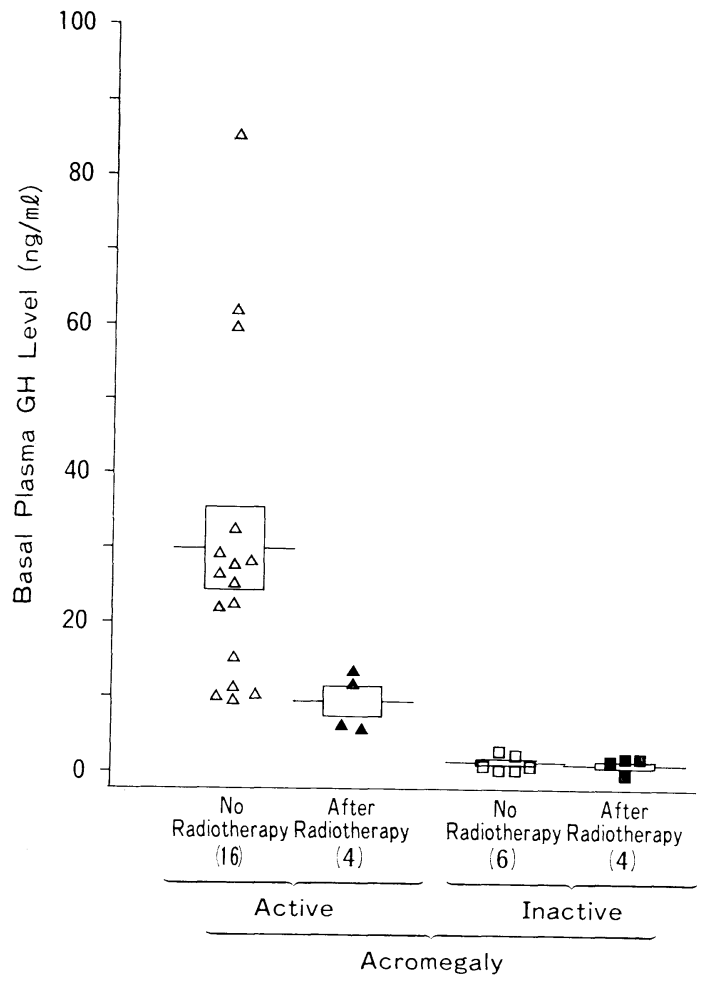

Fig. 18. Basal plasma GH levels in acromegalic patients in an active or inactive phase, who were subdivided to the groups with or without previous radiotherapy. not different from those in normal subjects (Fig. 19). Similar findings have been reported by other laboratories (Penny et al., 1984; Thorner et al., 1984). In this study, furthermore, we found no correlation between the basal GHRH-LI levels and activity of acromegaly, age, sex or previous therapy including radiotherapy. As mentioned previously, the source of GHRH-LI in peripheral plasma is not only the hypothalamus but also the extrahypothalamic site, expecially GEP system. Thus, no difference in basal plasma GHRH-LI levels between the groups was not unexpected. In contrast, plasma GHRH-LI responses to 1-dopa discriminated between the subjects with and without hypothalamic damage (Fig. 20). The net increment of plasma GHRH-LI after 1-dopa ingestion in patients with hypothalamic lesions like germinoma, craniopharyngioma, meningioma or irradiation to the hypothalamus, $-0.6 \pm 0.7 \mathrm{pg} / \mathrm{ml}$ was significantly lower than that in normal subjects $(+6.5$ $\pm 0.9 \mathrm{pg} / \mathrm{ml}$ ). Plasma GHRH-LI rises after 1-dopa administration occurred in acromegalic patients in an active phase as well as in an inactive phase, who have not treated with irradiation. Radiotheraphy $\square$

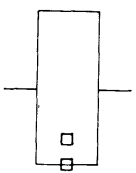

$\square$

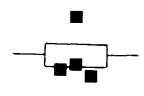

Fig. 19. Basal GHRH-LI levels in peripheral plasma in normal subjects, patients with hypothalamic lesions and acromegalic patients. Acromegalic patients were divided to four groups by their GH-secreting activity and the history of previous radiotherapy. 


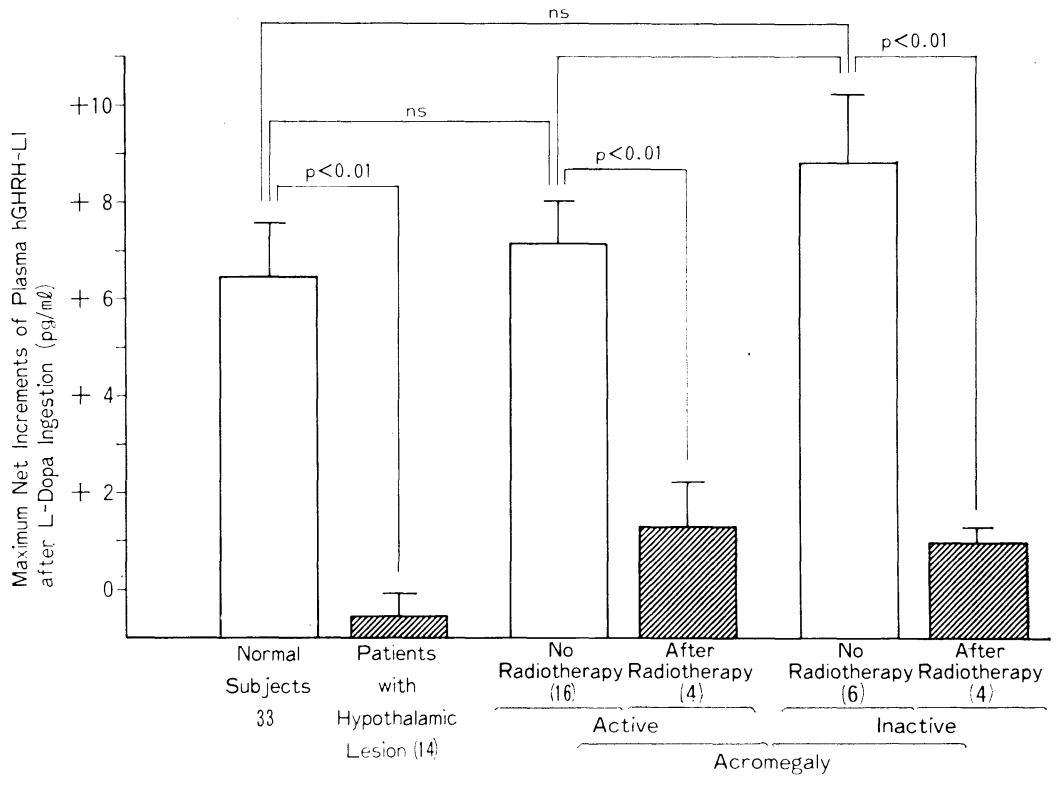

Fig. 20. Maximum net increments of plasma GHRH-LI after 1dopa ingestion in normal subjects, patients with hypothalamic lesions and acromegalic patients. Acromegalic patients were divided to four groups by their GH-secreting activity and the history of previous radiotherapy.

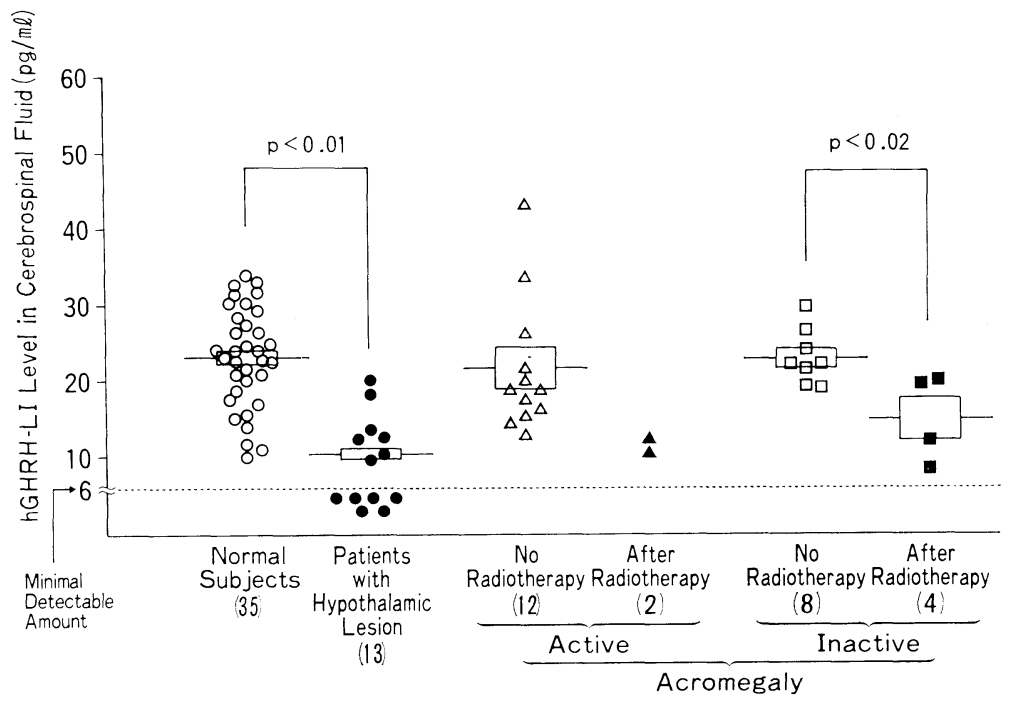

Fig. 21. GHRH-LI levels in the CSF in nomal subjects, patients with hypothalamic lesion and acromegalic patients. Acromegalic patients were divided to four groups by their GH-secreting activity and the history of previous radiotherapy.

caused significant attenuation of plasma GHRH-LI rise by 1-dopa irrespective of activity of acromegaly, suggesting impaired hypothalamic GHRH secretion resulting from hypothalamic damage by irradiation. These findings were consistent with the results of GHRH-LI in the CSF (Fig. 21). Acromegalic patients treated with radiotherapy had significantly lower GHRH-LI levels in the CSF as compared with those without radiotherapy.

It was of interest that acromegalic patients in an active phase had the GHRHLI levels in CSF comparable to those in normal subjects and exhibited plasma 
GHRH-LI increases after 1-dopa ingestion as normal |subjects did. Considering the presence of autoregulation mechanisms for GH secretion, one would expect the suppression of hypothalamic GHRH release as a result of negative feedback regulation by hypersecreted GH from pituitary tumor. Failure of suppressing hypothalamic GHRH release in active acromegaly may cause not only further stimulation of both synthesis and release of $\mathrm{GH}$ but also augmentation of tumor growth. Regarding the role of GHRH in activity of acromegaly, it was of great interest that the active acromegalic patients receiving radiotherapy showed not only the decreased hypothalamic GHRH-LI secretion but also the significantly lower plasma GH levels than the active acromegalic patients without radiotherapy. Therefore, persistent and inappropriate secretion of GHRH from the hypothalamus probably play a role in an activation or development of pituitary adenoma in at least some of the patients with active acromegaly. The mechanisms by which GHRH release is sustained in active acromegaly remain unknown and need further investigations.

\section{Acknowledgements}

This work was supported in part by research grants from the Japanese Ministry of Health and Welfare, from the Japanese Ministry of Education, Science and Culture and from the Growth Science Foundation.

\section{References}

Argente, J., D. Evain-Brion, A. Munoz-Villa, P. Garnier, M. Hernandez and M. Donnadieu (1986). Relationship of plasma growth hormone releasing hormone levels to pubertal changes. J. Clin. Endocrinol. Metab. 63, 680683.

Audhya, T., M. M. Manzione, T. Nakane, N. Kanie, J. Passarelli, M. Russo and C. S.
Hollander (1985). Levels of human and rat hypothalamic growth hormone-releasing factor as determined by specific [radioimmunoassay system. Proc. Natl. Acad. Sci. USA 82, 2970 $-2977$.

Baird, A., W. B. Wehrenberg, P. Böhlen and N. Ling (1985). Immunoreactive and biologically active growth hormone-releasing factor in the rat placenta. Endocrinology 117, 1598-1601.

Barinaga, M., G. Yamamoto, C. Rivier, W. Vale, R. Evans and M. G. Rosenfeld (1983). Transcriptional regulation of growth hormone gene expression by growth hormone-releasing factor. Nature 306, 84-86.

Borges, J. L. C., R. M. Blizzard, W. S. Evans, R. Furlanetto, A. D. Rogo, D. L. Kaiser, J. Rivier, W. Vale and M. O. Thorner (1984). Stimulation of growth hormone $(\mathrm{GH})$ and somatomedin $\mathrm{C}$ in idiopathic $\mathrm{GH}$-deficient subjects by intermittent pulsatile administration of synthetic human pancreatic tumor GHreleasing factor. J. Clin. Endocrinol. Metab. 59, 1-6.

Bosman, F. T., C. Van Assche, A. C. Nieuwenhuyzen Kruseman, S. Jackson and P. J. Lowry (1984). Growth hormone releasing factor (GRF) immunoreactivity in human and rat gastrointestinal tract and pancreas. J. Histochem. Cytochem. 32, 1139-44.

Bresson, J. L., M. C. Clavequin, D. Fellman, and C. Bugnon (1984). Ontogeny of the neuroglandular system revealed with hpGRF44 antibodies in human hypothalamus. Neuroendocrinology 39, 68-73.

Bruhn, T. O., R. T. Mason and W. W. Vale (1985). Presence of growth hormone-releasing factor-like immunoreactivity in rat duodenum. Endocrinology 117, 1710-1712.

Chihara, K., N. Minamitani, H. Kaji, H. Kodama, T. Kita and T. Fujita (1984). Noradrenergic modulation of human pancreatic growth hormone releasing factor (hpGRF1-44)-induced growth hormone release in conscious male rabbits: involvement of endogenous somatostatin. Endocrinology 114, 1402-1406.

Chihara, K., Y. Kashio, H. Abe, N. Minamitani, H. Kaji, T. Kita and T. Fujita (1985). Idiopathic growth hormone $(\mathrm{GH})$ deficiency, and GH deficiency secondary to hypothalamic germinoma : effect of single and repeated administration of human GH-releasing factor (hGRF) on plasma GH level and endogenous hGRF-like immunoreactivity level in cerebro- 
spinal fluid. J. Clin. Endocrinol. Metab. 60, 269-278.

Chihara, K., Y. Kashio, T. Kita, Y. Okimura, H. Kaji, H. Abe and T. Fujita (1986). LDopa stimulates release of hypothalamic growth hormone-releasing hormone in humans. $J$. Clin. Endocrinol. Metab. 62, 466-473.

Donnadieu, M., D. Evain-Brion, M. C. Tonon, H. Vaudry and J.-C. Job. (1985). Variations of plasma growth hormone $(\mathrm{GH})$-releasing factor levels during $\mathrm{GH}$ stimulation tests in children. J. Clin. Endocrinol. Metab. 60, 1132-1134.

Finkelstein, J. W., H. P. Roffwarg, R. M. Boyar, J. Kream and L. Hellman (1972). Age-related changes in the twenty-four hour spontaneous secretion of growth hormone. J. Clin. Endocrinol. Metab. 35, 665-670.

Frohman, L. A. (1984). Growth hormone releasing factor-A neuroendocrine perspective. J. Lab. Clin. Med. 103, 819.

Frohman, L. A. and J.-O. Jansson (1986). Growth hormone-releasing hormone. Endocrine Review 7, 223-253.

Frohman, L. A., T. R. Downs, T. C. Williams, E. P. Heimer, Y-C. E. Pan and A. Felix (1986). Rapid enzymatic degradation of growth hormone releasing hormone (GRH) by plasma in vitro and in vivo to a biologically inactive $\mathrm{N}$-terminally cleaved product. J. Clin. Invest. 78, 906-913.

Gelato, M. C., G. R. Merriam, M. L. Vance, J. A. Goldman, C. Webb, et al (1985). Effects of growth hormone-releasing factor upon growth hormone secretion in acromegaly. $J$. Clin. Endocrinol. Metab. 60, 251-257.

Gelato, M. C., J. L. Ross, S. Malozowski, O. H. Pescovitz, M. Skerd, F. Cassorla, D. L. Loriaux and G. R. Merriam (1985). Effects of pulsatile administration of growth hormone (GH)-releasing hormone on short term linear growth in children with $\mathrm{GH}$ deficiency. J. Clin. Endocrinol. Metab. 61, 444-451.

Gelato, M. C. and G. M. Merriam (1986). Growth hormone releasing hormone. Ann. Rev. Physiol. 48, 569-591.

Goodman, H. G., M. M. Grumback and S. L. Kaplan (1968). Growth and growth hormone. II. A comparison of isolated growth hormone deficiency and multiple pituitary hormone deficiencies in 35 patients with idiopathic hypopituitary dwarfism. N. Engl. J. Med. 278, 57-68.

Kashio, Y., K., Chihara, H. Kaji, N. Minamitani,
T. Kita, Y. Okimura, H. Abe, J. Iwasaki and T. Fujita (1985). Presence of growth hormonereleasing factor-like immunoreactivity in human cerebrospinal fluid. J. Clin. Endocrinol. Metab. 60, 396-398.

Kaplan, S. L. and M. M. Grumbach (1976). Development of hormonal secretion by the human fetal pituitary gland. In: Frontiers in Neuroendocrinology Vol. 4 (L. Martini and W. F. Ganong eds.) Raven Press, New York. pp 255-276.

Li, J. Y., M. P. Dubois and P. M. Dubois (1977). Somatotrophs in human fetal anterior pituitary. Cell Tissue Res. 181, 545-552.

Lin, H. D., J. Bollinger, N. Ling and S. Reichlin (1984). Immunoreactive growth hormone-releasing factor in human stalk median eminence. J. Clin. Endocrinol. Metab. 58, 1197-1199.

Ling, N., F. Esch, P. Böhlen, P. Brazeau, W. B. Wehrenberg and R. Guillemin (1984). Isolation, primary structure, and synthesis of human hypothalamic somatocrinin: growth hormonereleasing factor. Proc. Natl. Acad. Sci. USA 81, 4302-4306.

Martin, J. B., P. Brazeau, G. S. Tannenbaum, J. O. Willoughby, J. Epelbau, L. C. Terry and D. Durand (1978). Neuroendocine organization of growth hormone regulation. In: The Hypothalamus (S. Reichlin, R. J. Baldessarini and J. B. Martin eds.) Ravan Press, New York. pp. 329-357.

Matsuzaki, F., M. Irie and K. Shizume (1971). Growth hormone in human fetal pituitary glands and cord blood. J. Clin. Endocrinol. Metab. 33, 908-911.

Miki, N., M. Ono and K. Shizume (1984). Evidence that opiatergic and $\alpha$-adrenergic mechanisms stimulate rat growth hormone release via growth hormone-releasing factor (GRF). Endocrinology 114, 1950-1953.

Morel, G., P. Mesguich, M. P. Dubois and P. M. Dubois (1984). Ultrastructural evidence for endogenous growth hormone-releasing factor-like immunoreactivity in the monkey pituitary gland. Neuroendocrinology 38, 123133.

Pandol, S. J., H. Seifert, M. W. Thomas, J. Rivier and W. Vale (1984). Growth hormonereleasing factor stimulates pancreatic enzyme secretion. Science 225, 326-328.

Penny, E. S., E. Penman, J. Price, L. H. Rees, A. M. Sopwith, J. A. H. Wass, N. Lytras and G. M. Besser (1984). Circulating growth 
hormone releasing factor concentrations in normal subjects and patients with acromegaly. Br.Med. J. 289, 453-455.

Penny, E. S., R. L. Patience, A. M. Sopwith, J. A. H. Wass, G. M. Besser and L. H. Rees (1985). Characterization by high performance liquid chromatography of circulating growth hormone releasing factors in a human plasma. J. Endocr. 105, R1-4.

Reichlin, S., R. Saperstein, I. M. D. Jackson, A. E. III Boyd and Y. Patel (1976). Hypothalamic hormones. Ann. Rev. Physiol. 38, 389 -424 .

Saito, H., S. Saito, R. Yamazaki and E. Hosoi (1984). Clinical value of radioimmunoassay of plasma growth hormone-releasing factor. Lancet 2, 401.

Shibasaki, T., K. Shizume, A. Masuda, M. Nakahara, N. Hizuka et al. (1984). Plasma growth hormone response to growth hormone releasing factor in acromegalic patients. $J$. Clin. Endocrinol. Metab. 58, 215-217.

Shibasaki, T., Y. Kiyosawa, A. Masuda, M. Nakahara, T. [Imaki, I. Wakabayashi, H. Demura, K. Shizume and N. Ling (1984). Distribution of growth hormone-releasing hormone-like immunoreactivity in human tissue extracts. J. Clin. Endocrinol. Metab. 59, 263268.
Shibasaki, T., M. Hotta, A. Masuda, T. Imaki, N. Obara, H. Demura, N. Ling and K. Shizume (1985). Plasma GH responses to GHRH and insulin-induced hypoglycemia in man. J. Clin. Endocrinol. Metab. 60, 1265-1267.

Thorner, M. O., L. A. Frohman, D. A. Leong, J. Thominet, T. Downs, P. Hellmann, J. Chitwood, J. M. Vaughan and W. Vale (1985). Extrahypothalamic growth-hormone-releasing factor (GRF) secretion is a rare cause of acromegaly: plasma GRF levels in 177 acromeglic patients. J. Clin. Endocrinol. Metab. 59, 846-849.

Vale, W., C. Rivier and M. Brown (1977). Regulatory peptides of the hypothalamus. Ann. Rev. Physiol. 39, 473-527.

Vance, M. L., D. L. Kaiser, J. Rivier, W. Vale and M. O. Thorner (1986). Dual effects of growth hormone $(\mathrm{GH})$-releasing hormone infusion in normal men: somatotroph desensitization and increase in releasable GH. $J$. Clin. Endocrinol. Metab. 62, 591-594.

Wood, S. M., J. L. C. Ch'ng, E. F. Adams, J. D. Webster, G. F. Joplin, et al. (1983). Abnormalities of growth hormone release in response to human pancreatic growth hormone releasing factor (GRF (1-44)) in acromegaly and hypopituitarism Br. Med. J. 286, 1687-1691. 